\title{
ROTATION MOVEMENTS OF THE SPINE WITH SPECIAL REFERENCE TO SCOLIOSIS
}

\author{
ROBERT RoAf, OSWESTRy, ENGLAND
}

In the latter half of the nineteenth and early part of the twentieth centuries surgeons and anatomists studied the movements of the spinal column, both in the living and in the cadaver (Weber and Weber 1836, Schulthess 1899, Lovett 1905, Virchow 1907, Fick 1910, Strasser 1913). These researches culminated in the work of Lovett (1905), who concluded that the spine is a tube of unequal flexibilities, that rotation and lateral bending are inevitably linked, that rotation does not occur in the lumbar region, and that side-bending does not occur in the thoracic region. Lovett stated: " in forward flexion, lateral flexion is associated with rotation to the convex side. In extension, lateral flexion is associated with rotation to the concave side." He did not state what happens in the neutral position. Lovett also implied that scoliosis is an exaggeration of a normal movement and that the mechanism of its production can be deduced from a study of models exaggerating one or other feature of unequal flexibilities.

Frazer (1940) assumed that the axis of rotation is in the centre of the vertebral body. From this assumption he concluded that the shape of the articular facets prevents rotation in the lumbar region or side-bending in the thoracic region.

It will be clear that observation of the movements of the vertebral bodies in the adult model is necessarily indirect. In the formalin-hardened cadaver the intervertebral disc loses its normal plasticity, and the post-mortem specimen does not necessarily reproduce exactly the movements of the living spine. Furthermore, the older investigators were influenced by a priori considerations and had not accepted the concept of an inconstant axis of movement in joints.

With the development of radiology, spinal movements have been reinvestigated and, first, flexion, extension, and, more recently, side-bending movements have been studied (Bakke 1931, Brailsford 1934, Steindler 1929, Tanz 1950, Begg and Falconer 1949, Wiles 1935). There has, however, been comparatively little recent work on rotation movements, either in the living subject or in fresh, flexible, necropsy specimens. It seemed, therefore, worth re-examining 1) the normal movements of the spine, noting in particular whether the spine does, in fact, behave as a tube of unequal flexibilities and whether side-bending and rotation are inevitably linked; and 2) the relationship between movements of the normal spine and the deformity of scoliosis.

\section{MATERIAL FOR STUDY}

For the purpose of this investigation there were two sources of material: 1) spines of stillborn babies, first preserved by freezing and then dissected free of all muscles after thawing; and 2) radiological examination of the spines of normal children. The results of these investigations are represented in Figures 1 to 9 and may be summarised as follows.

The young spine is a tube of roughly equal flexibilities; the axis of rotation is in the region of the posterior longitudinal ligament; lateral flexion and rotation normally occur independently and in both the thoracic and lumbar regions. It is true that, in the cervical region rotation is associated with a slight screwing-up on the side away from the direction of rotation and screwing-down on the opposite side. Finally, severe scoliosis is not just an exaggeration of a normal movement: it is fundamentally an abnormal rotation-often three to four times the normal range and deserves to be called a luxation, as the ancients called it. 


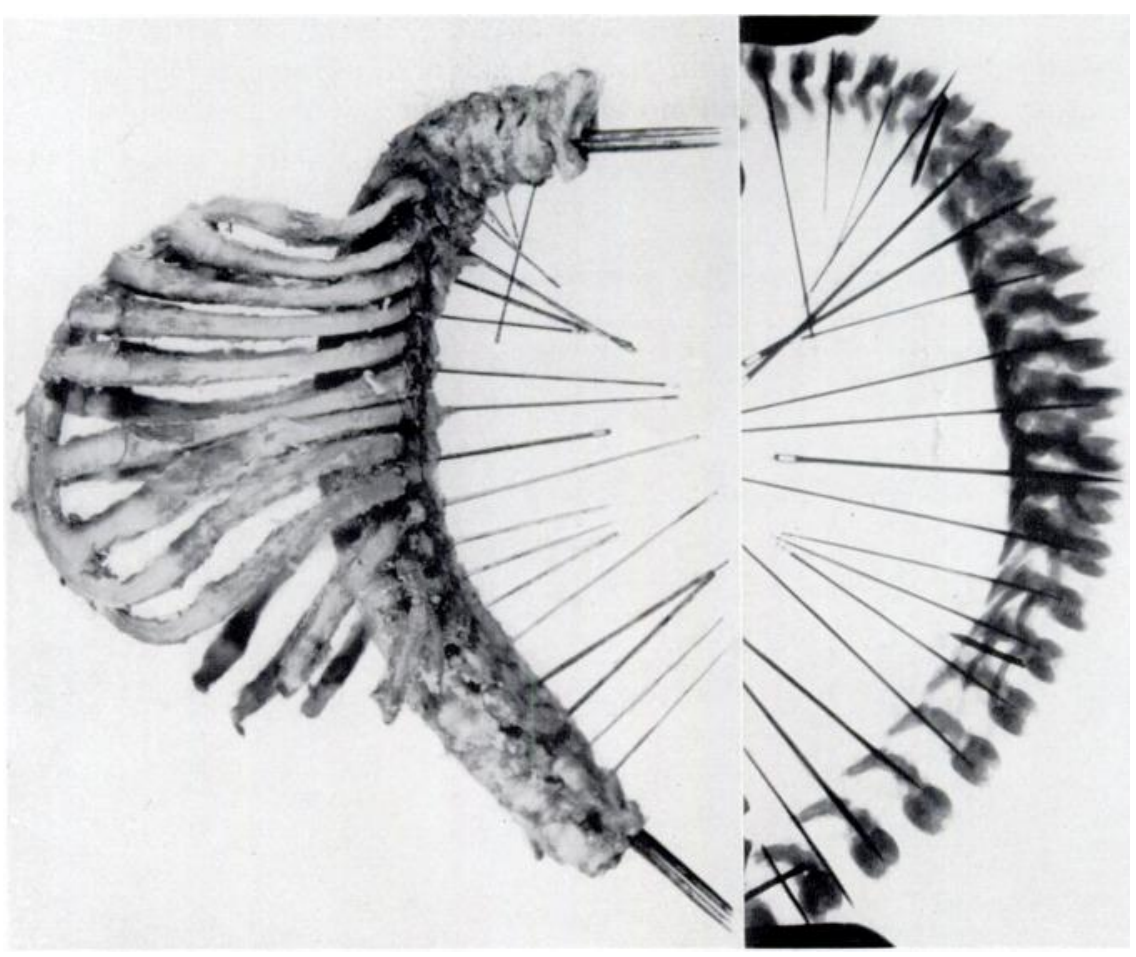

FIG. 1

Extension of normal infant's spine.

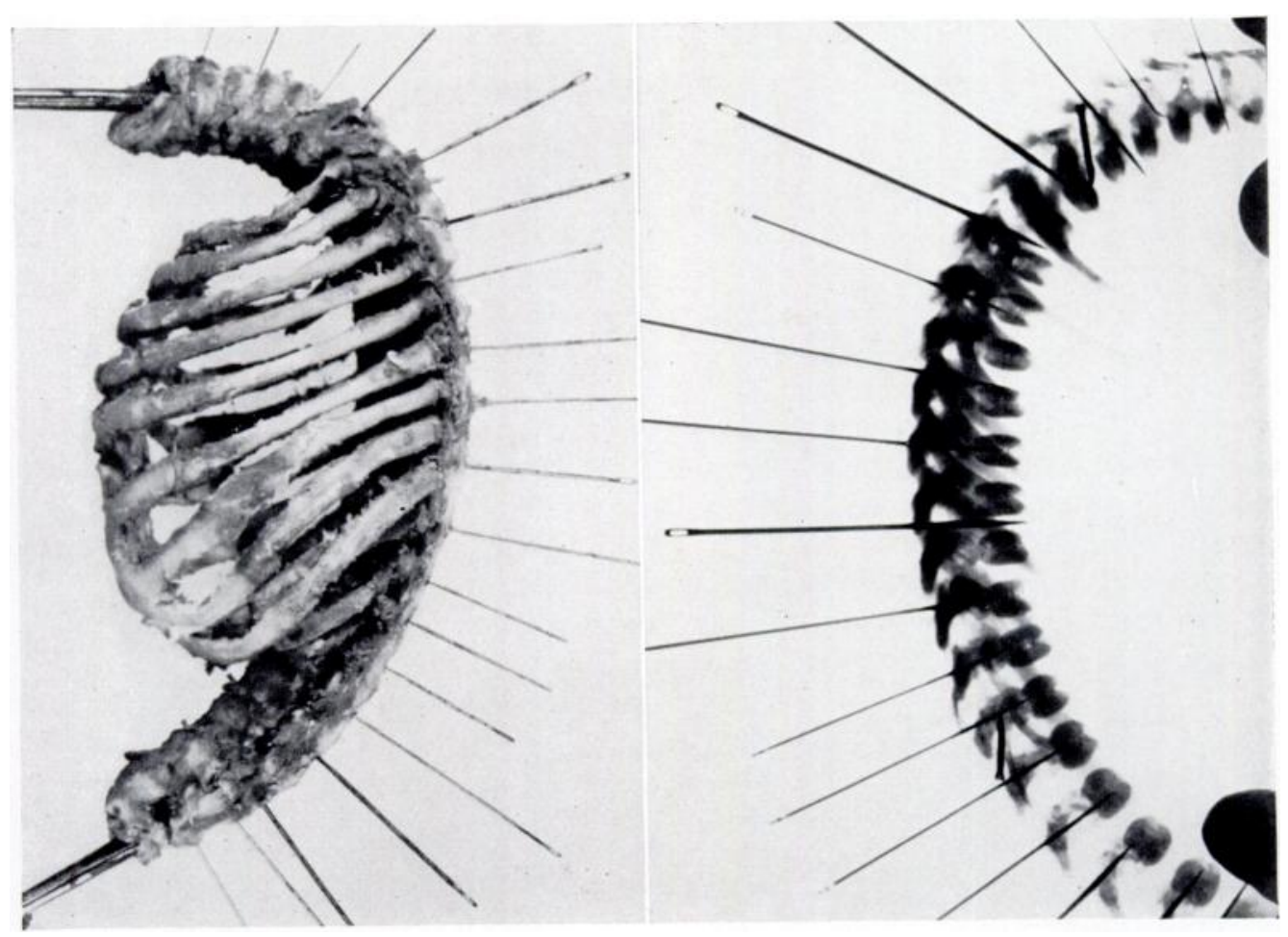

Fig. 2

Flexion of normal infant's spine.

vol. $40 \mathrm{~B}$, NO. 2, MAY 1958 
It will be realised 1) that there is a certain degree of individual variation; 2) that the axis about which rotation occurs may shift just as the axis of flexion-extension does; and 3) that the degree and nature of intervertebral movement is affected by the turgidity of the nucleus pulposus-for instance, decompressing the nucleus pulposus by making a tiny incision in the annular fibres and extracting the nucleus pulposus causes a big increase in lateral sliding and rotation between the vertebral bodies.

This is not the place to discuss the bearing these observations have on referred spinal pain, except to say that such pain is usually due to disorders of rotation and that this is the key to rational treatment.

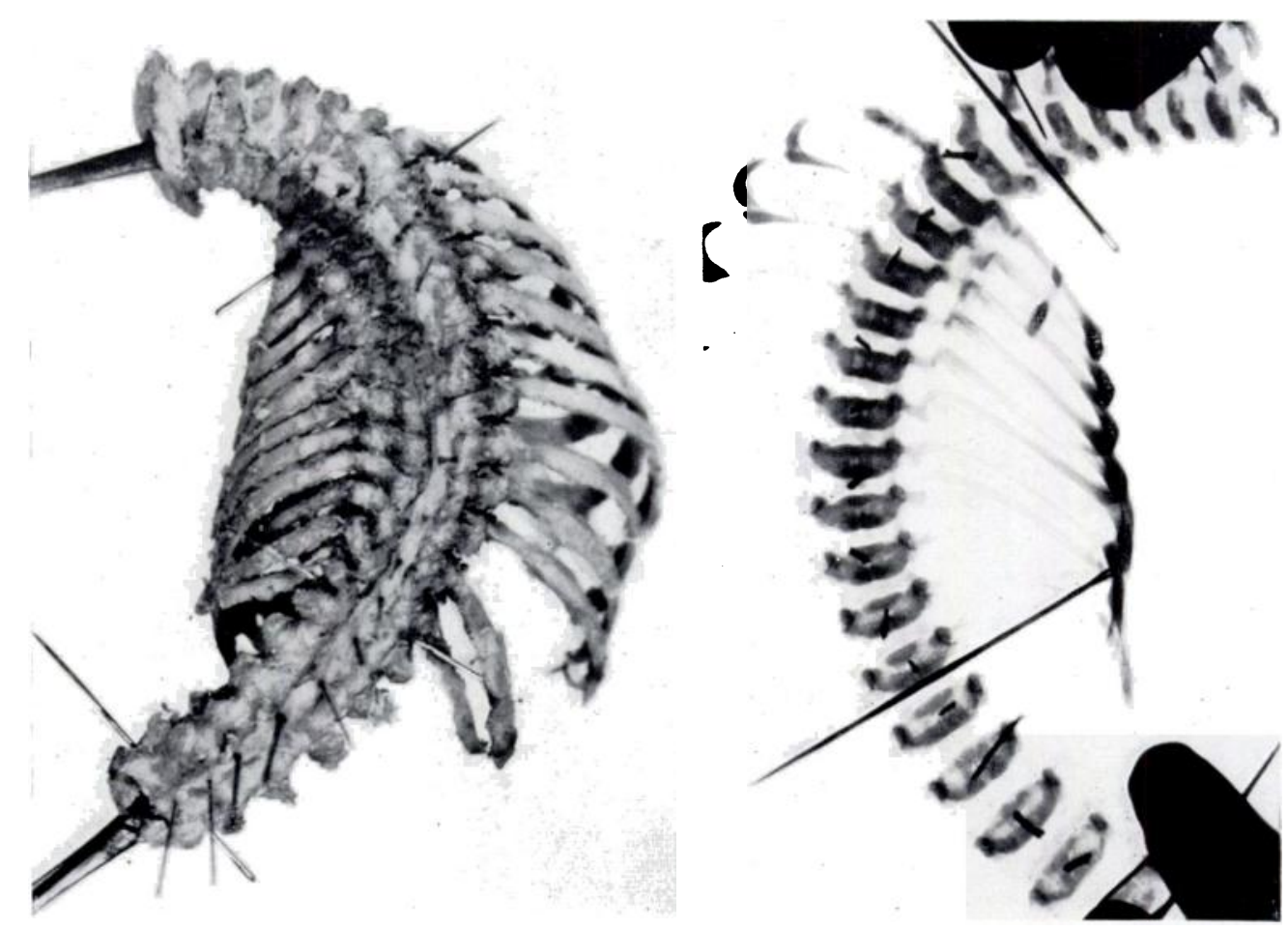

Fig. 3

Side-bending of normal infant's spine. Note absence of rotation.

To return to scoliosis, even if the spine is artificially converted into a tube of unequal flexibilities, it cannot be made to assume the usual deformity of scoliosis (Somerville 1952) (Figs. 10 to 15). In order to reproduce a scoliotic deformity one must divide most of the spinal ligaments and then realign the vertebrae in positions of forced rotation (Figs. 16 to 19).

It is worth noting that if, say, the direction of rotation is clockwise in the upper part of the curve, it must be anti-clockwise in the lower part (Fig. 20).

There are two types of scoliosis, which occur independently of etiology. The first is an uncommon type in which lateral flexion is the dominant element. The curve usually remains relatively mobile, is fairly easily corrected, has less tendency to relapse after fusion, and presents minimal rib deformity; basically it is an exaggeration of a normal movement (Fig. 21).

The other type of curve, in which rotation is the main feature, tends to be progressive; it soon becomes rigid and resistant to correction, and tends to relapse after fusion for two reasons. Firstly, there is an internal torsion and asymmetry of the vertebrae themselves which 

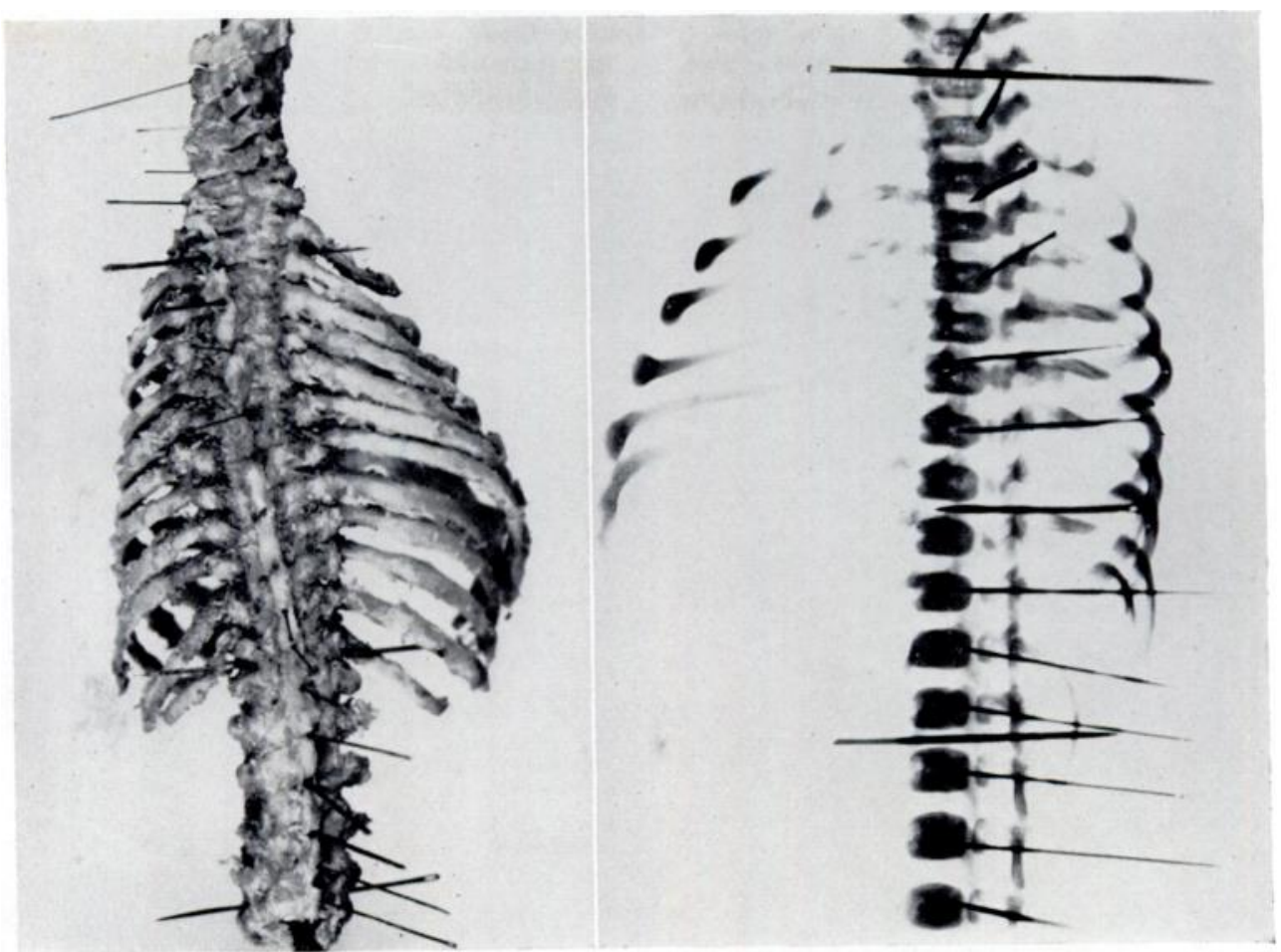

Fig. 4

Rotation. Note absence of side-bending.
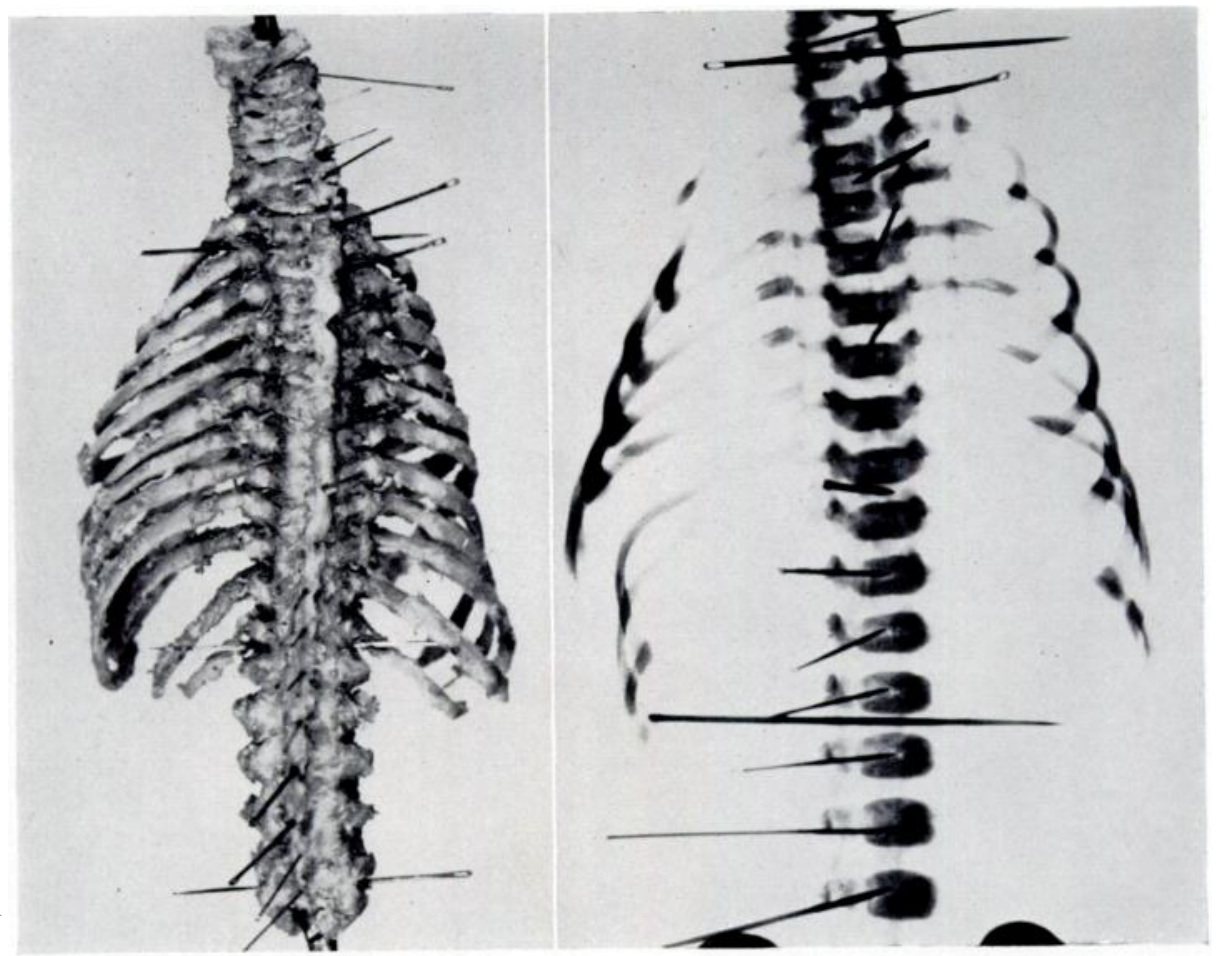

Fig. 5

Rotation. Note absence of side-bending.

VOL. 40 B, NO. 2, MAY 1958 


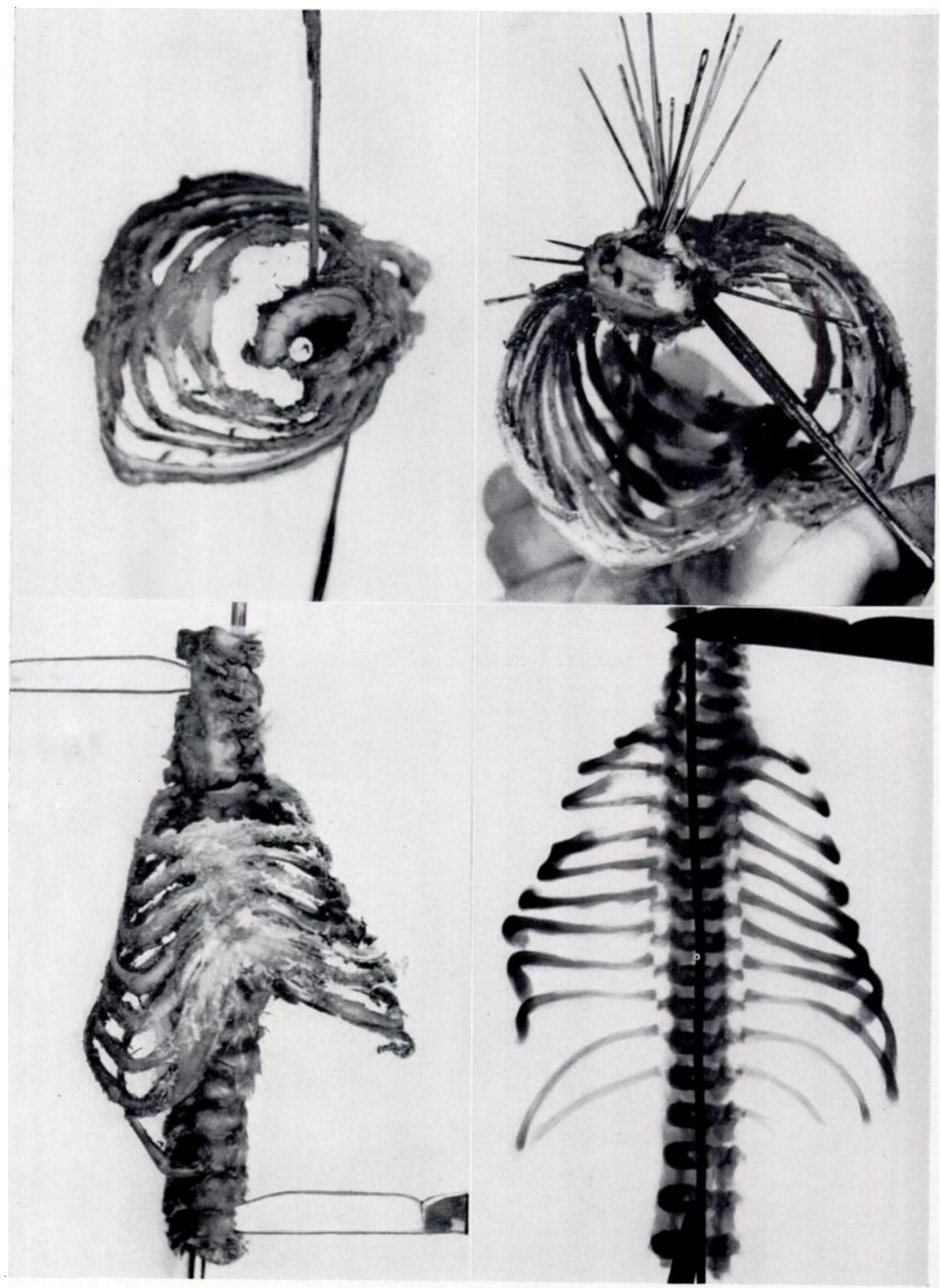

Fig. 6

Rotation. The axis of rotation is in the region of the posterior longitudinal ligament. Note that all movements are roughly equal and evenly distributed throughout the spine. 


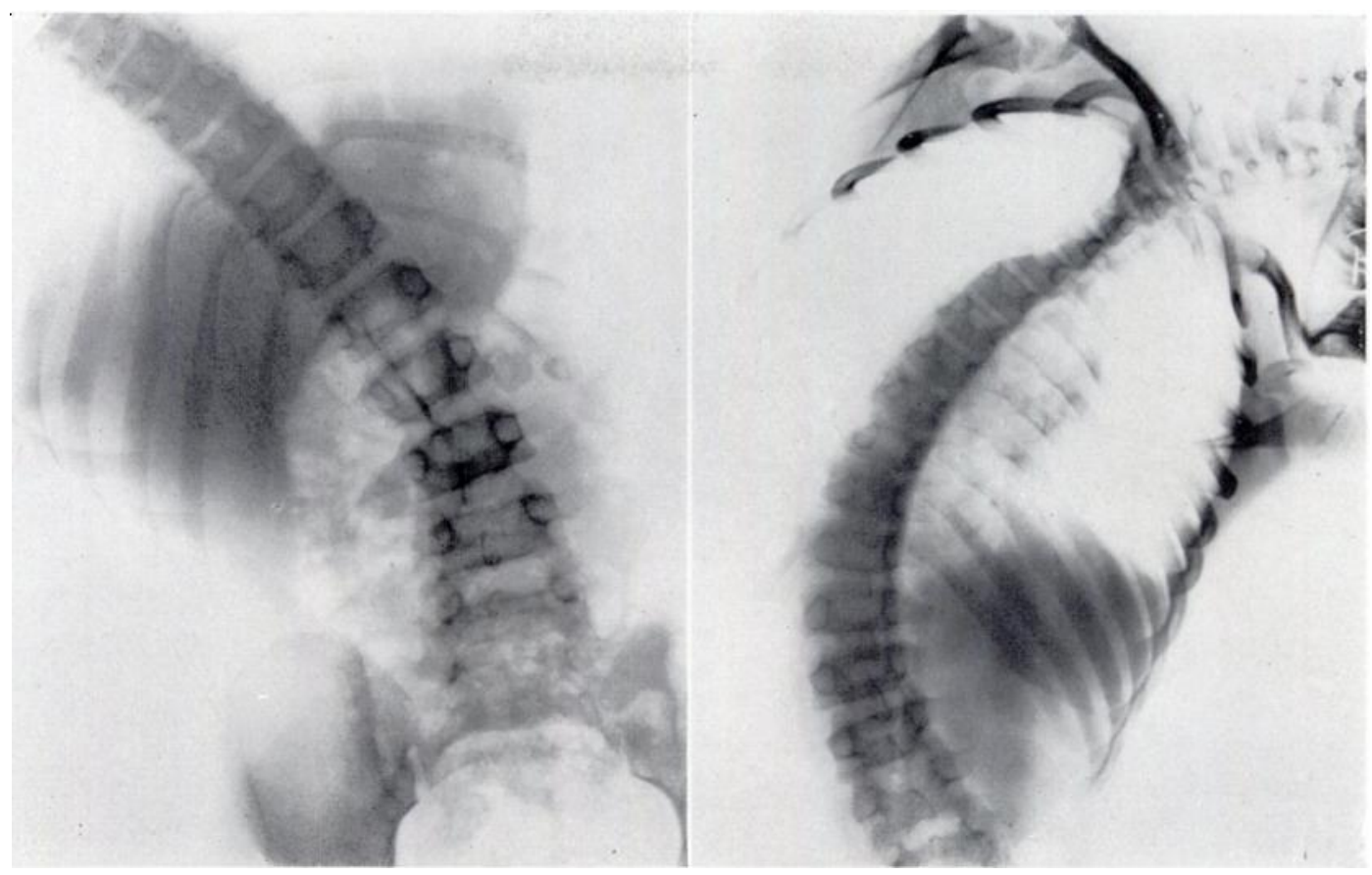

Fig. 7

Spine of eight-year-old boy, in lateral flexion. Note absence of rotation.
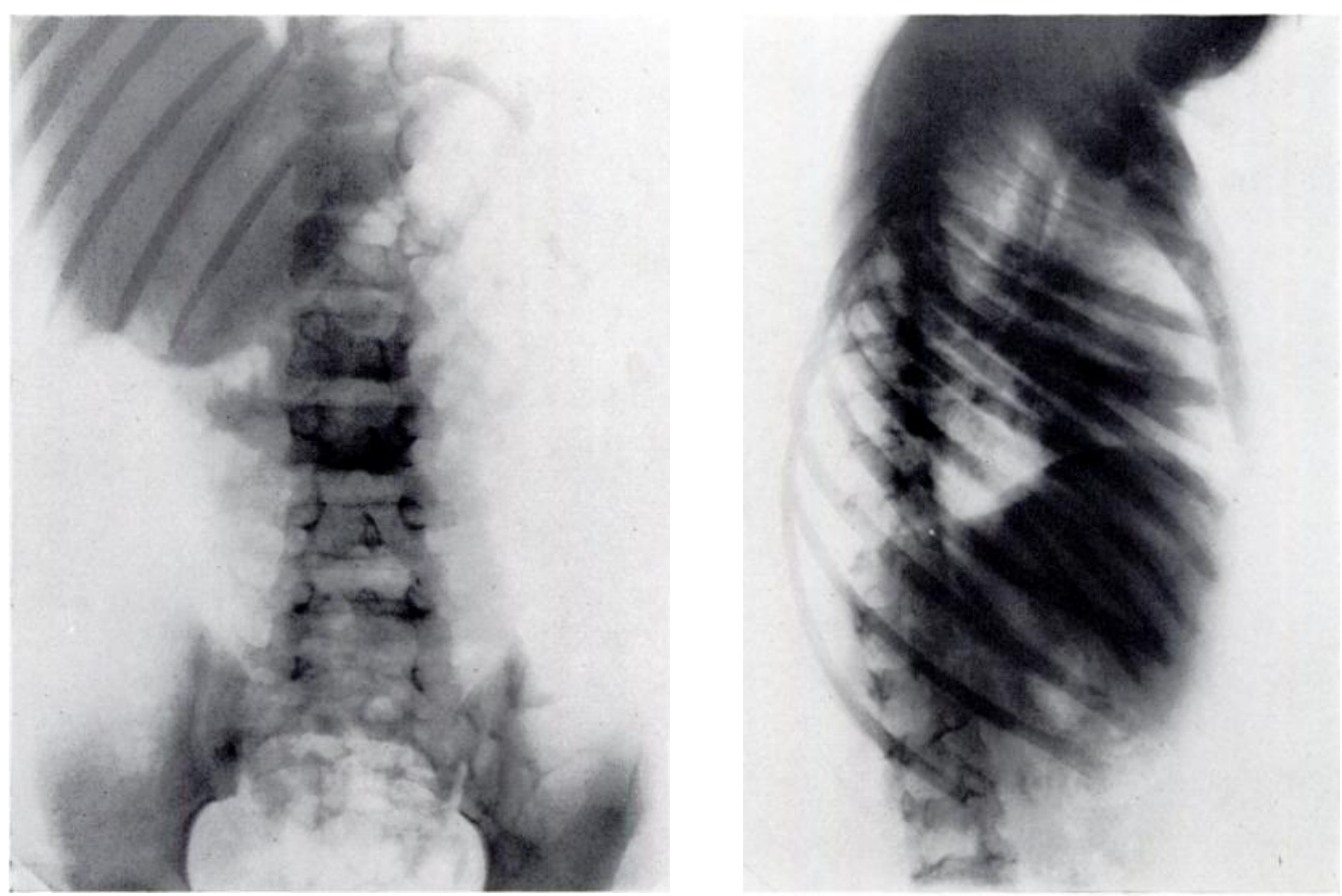

Fig. 8

Spine of eight-year-old boy, in rotation. Note absence of side-bending.

vol. 40 B, NO. 2, MAY 1958 


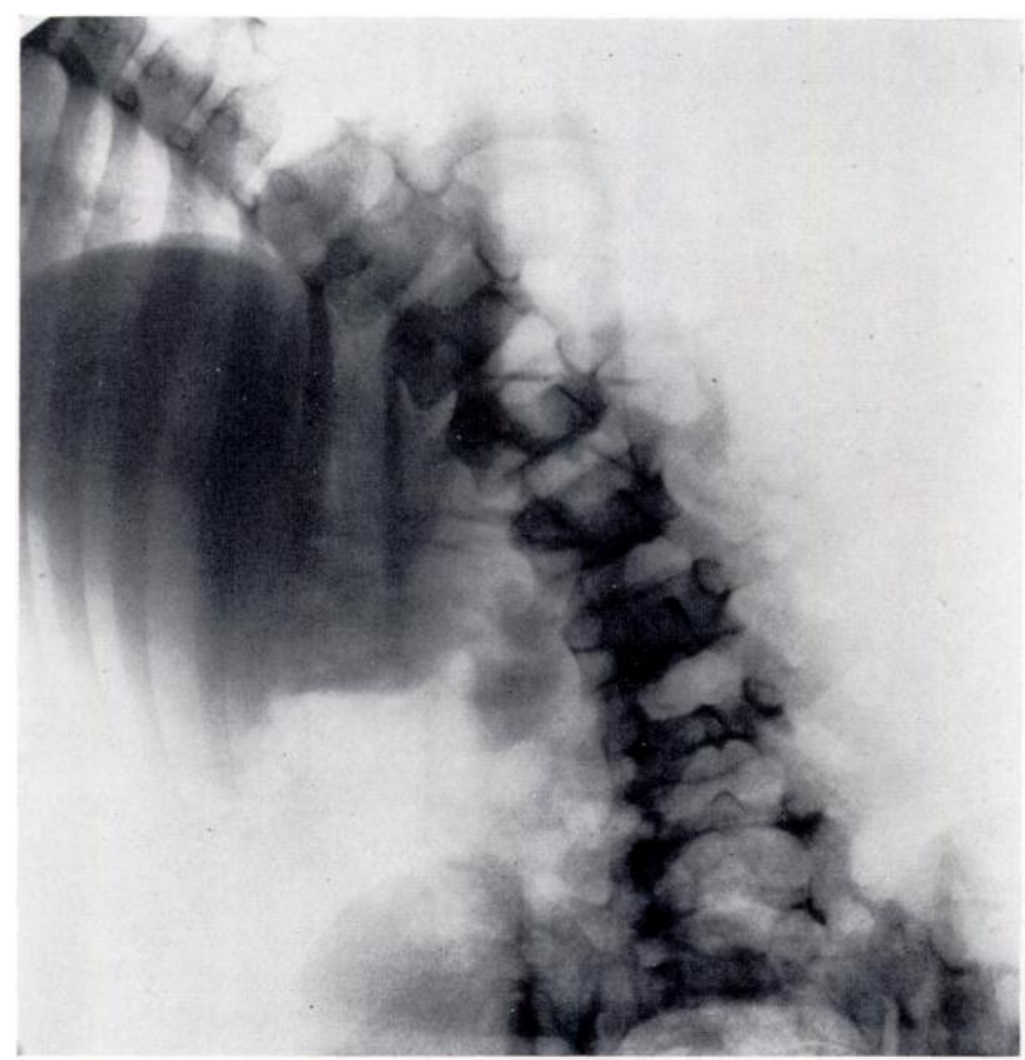

FIG. 9

Spine of eight-year-old boy. If an effort is made to combine rotation and sidebending, the result is rotation and forward flexion.
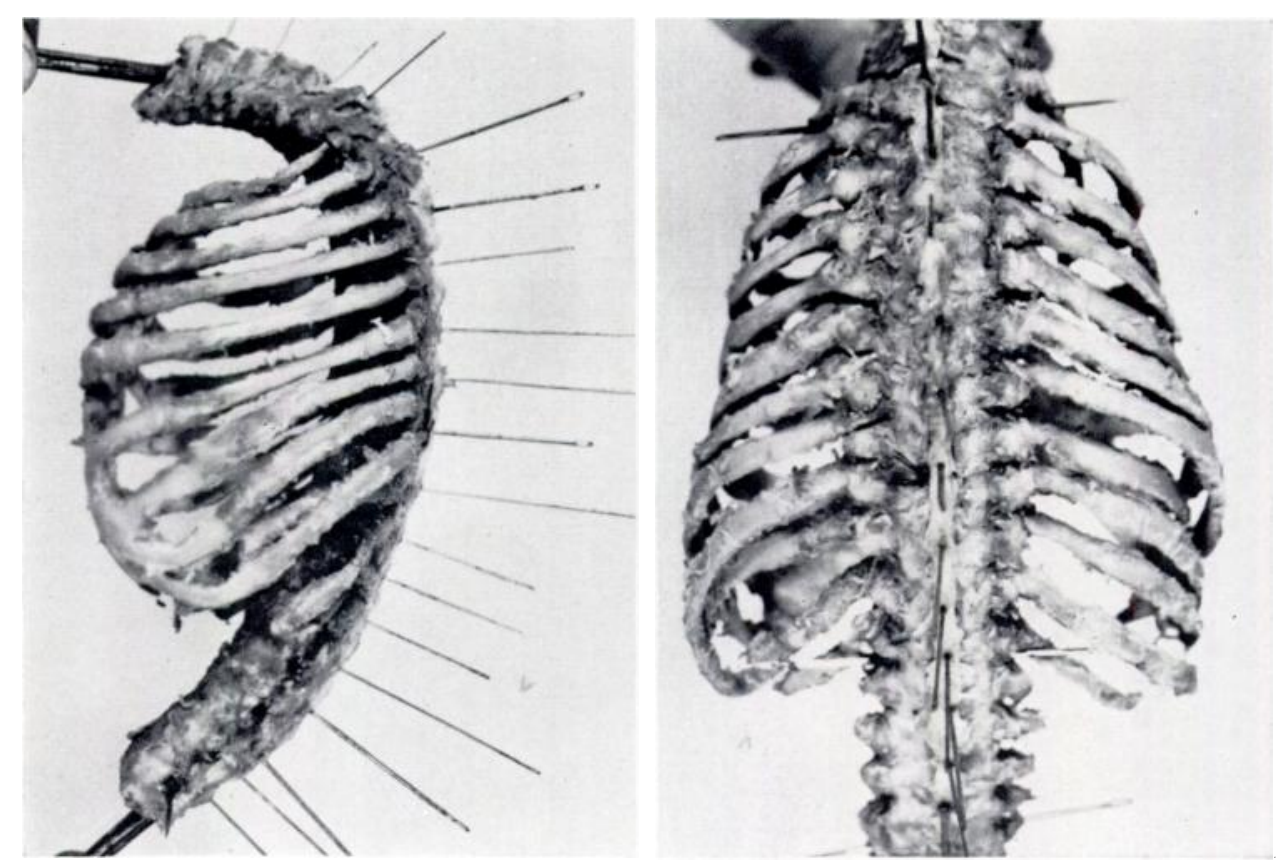

Fig. 10

Three spinous processes have been fastened together. In forced flexion there is no tendency to rotation.

THE JOURNAL OF BONE AND JOINT SURGERY 


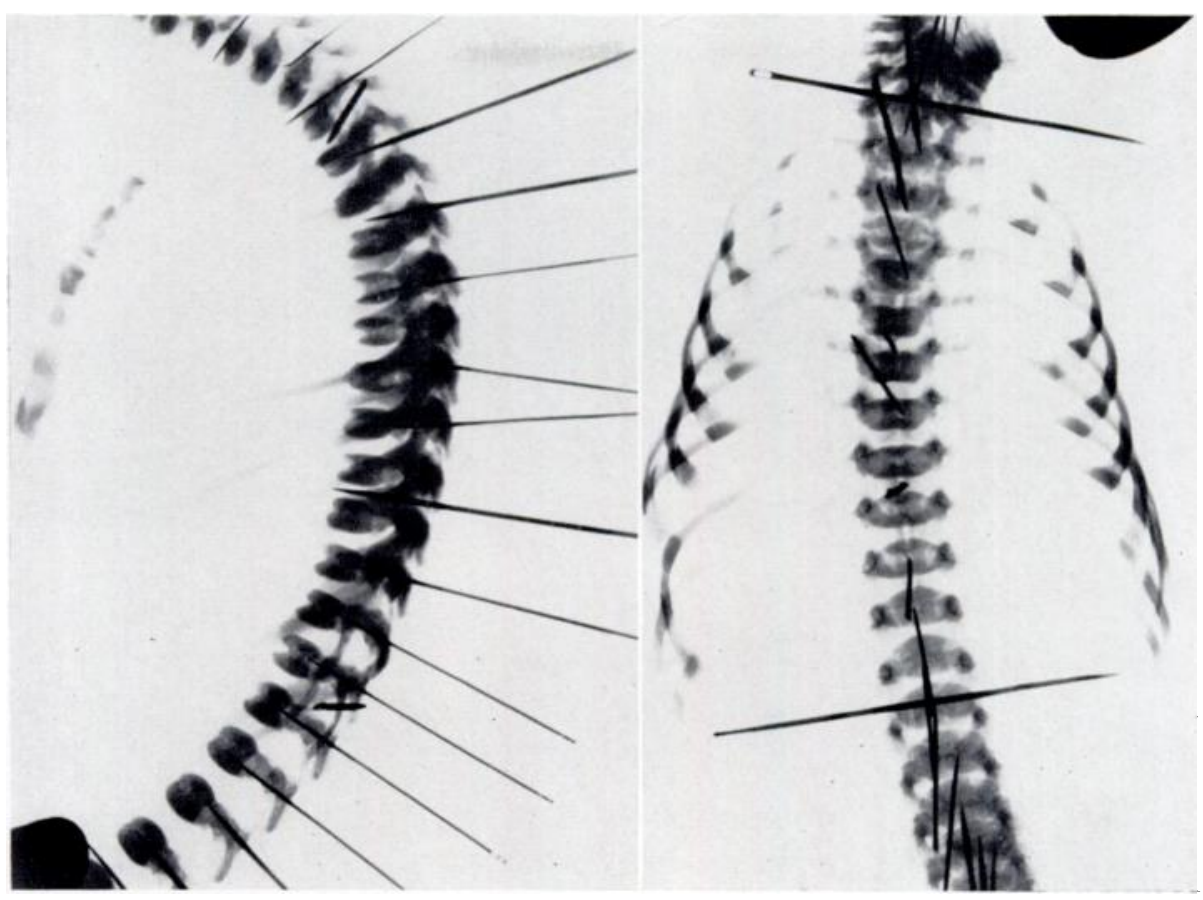

Fig. 11

Same spine as in Figure 10, radiographed in forced flexion. No tendency to rotation.

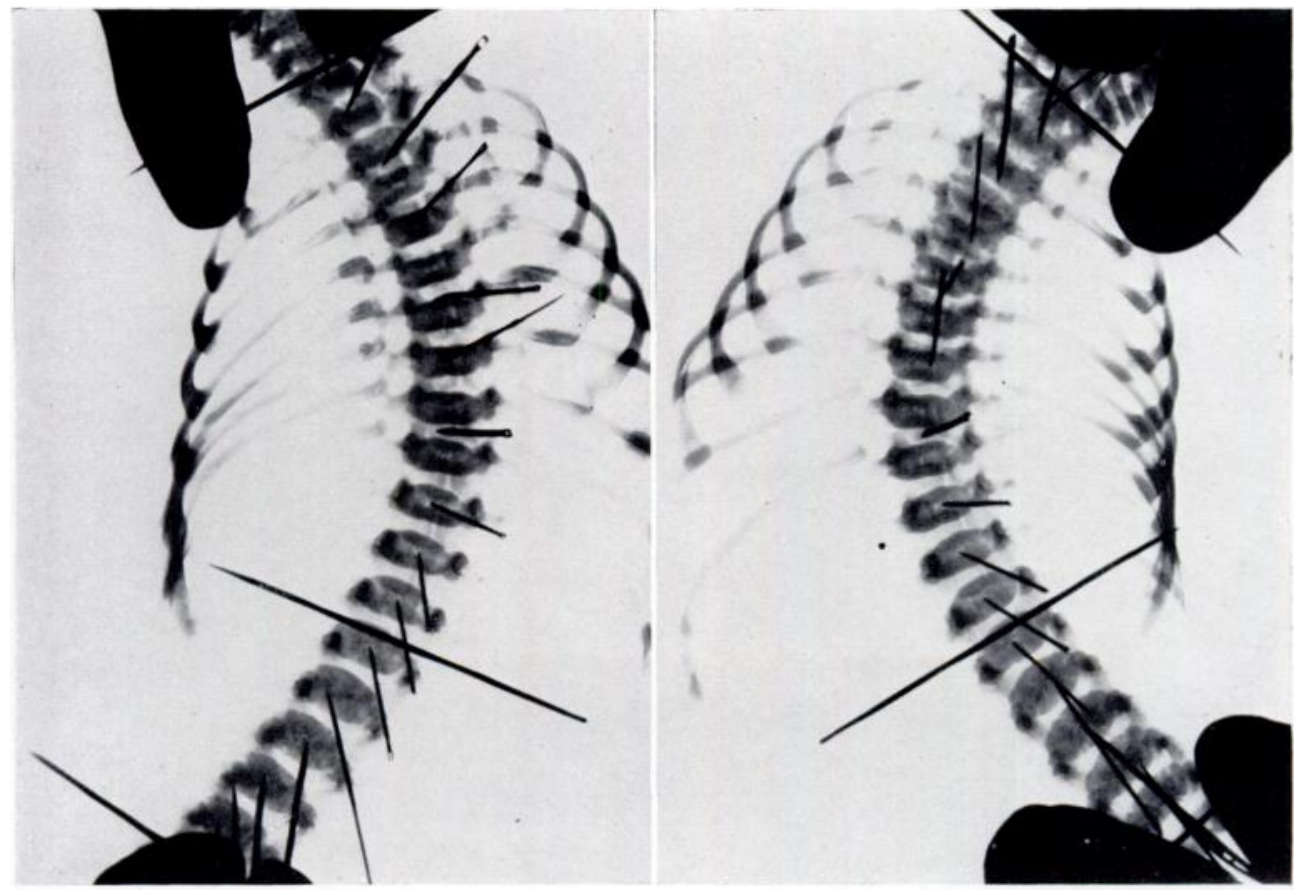

FIG. 12

Same spine as in Figures 10 and 11, radiographed in forced lateral flexion. No tendency to rotation. ']d 

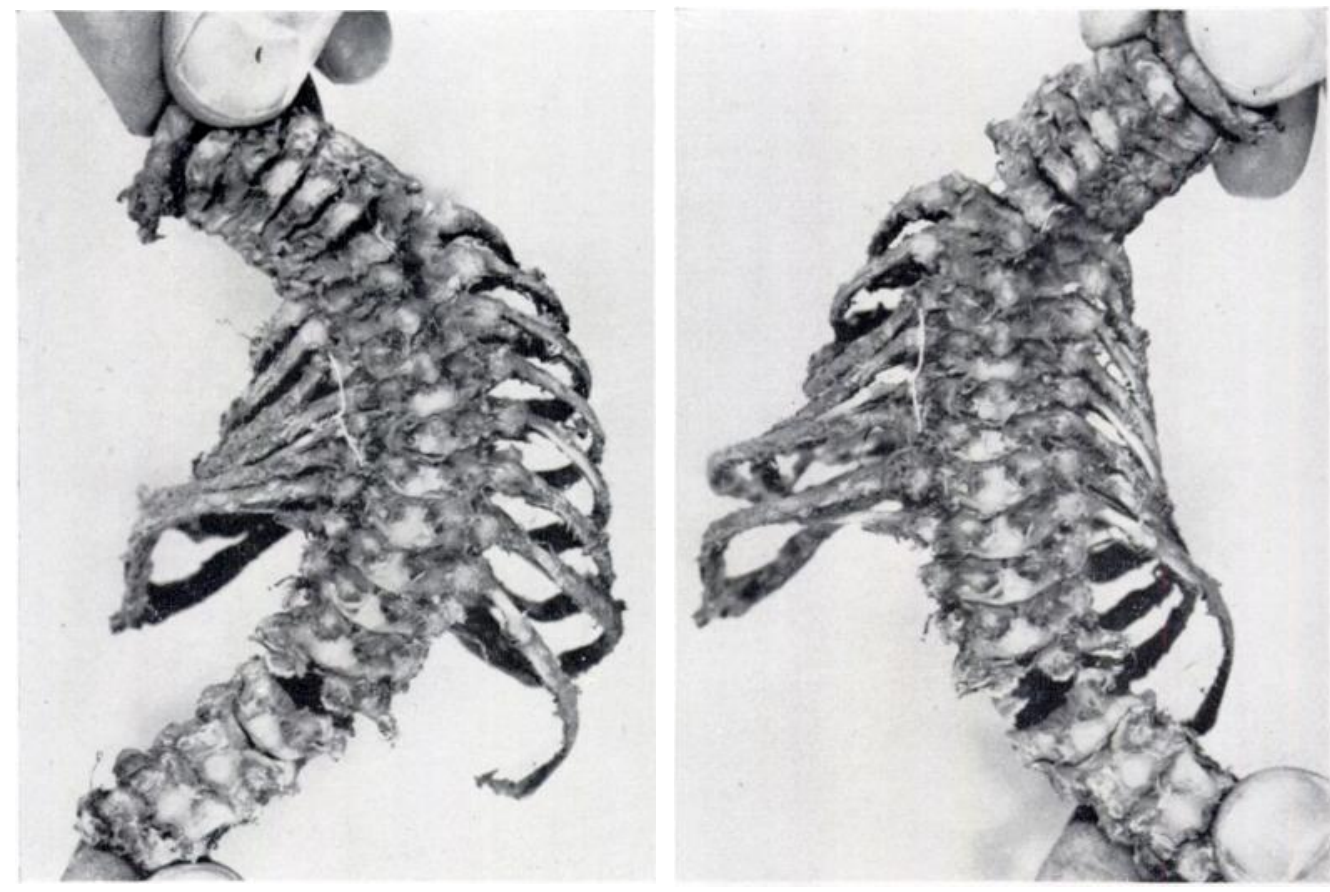

FIG. 13

Three transverse processes have been fastened together. In side-bending to the left or right there is no tendency to rotation.

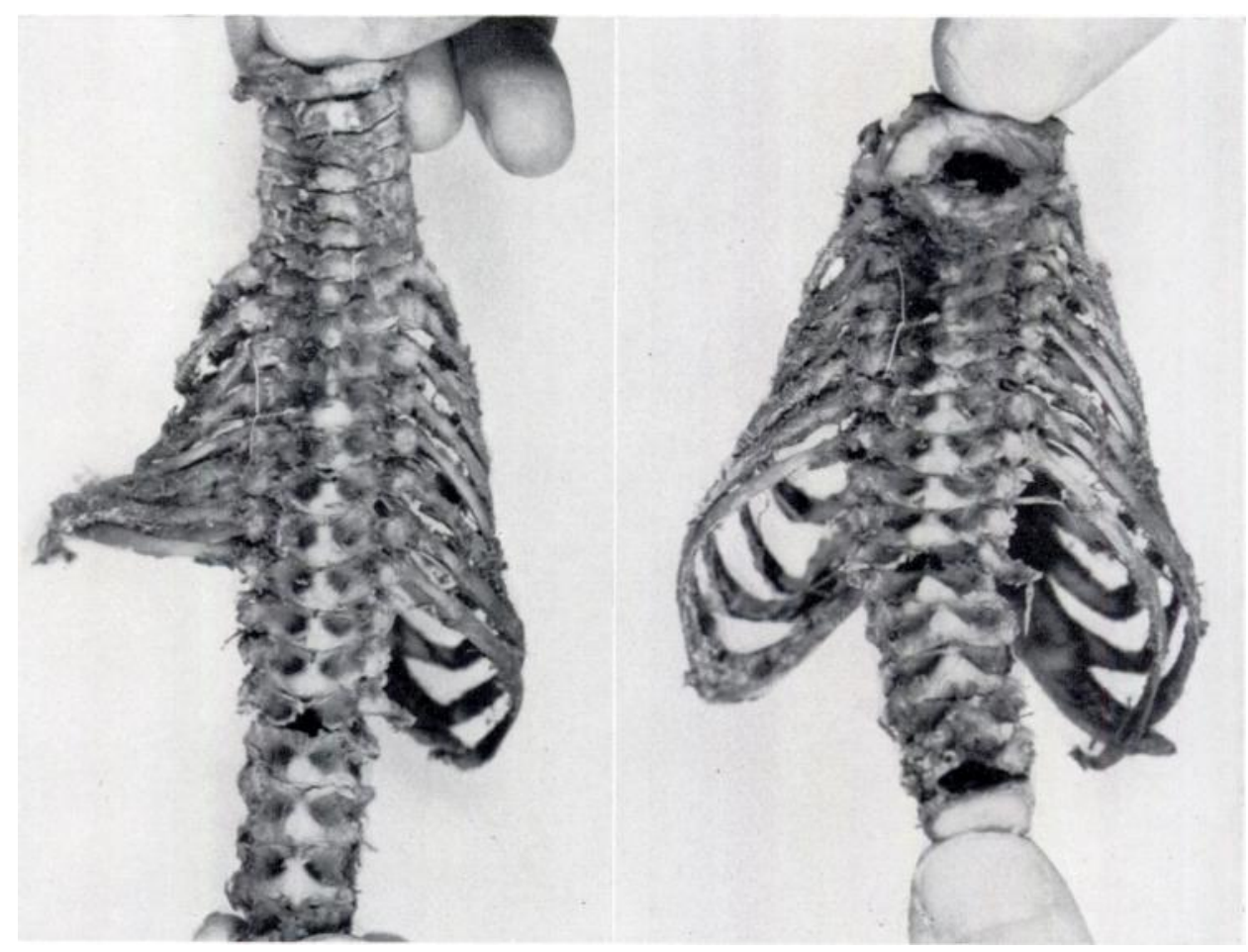

FIG. 14

Same spine as in Figure 13. In extension or flexion there is no tendency to rotation or lateral flexion. 

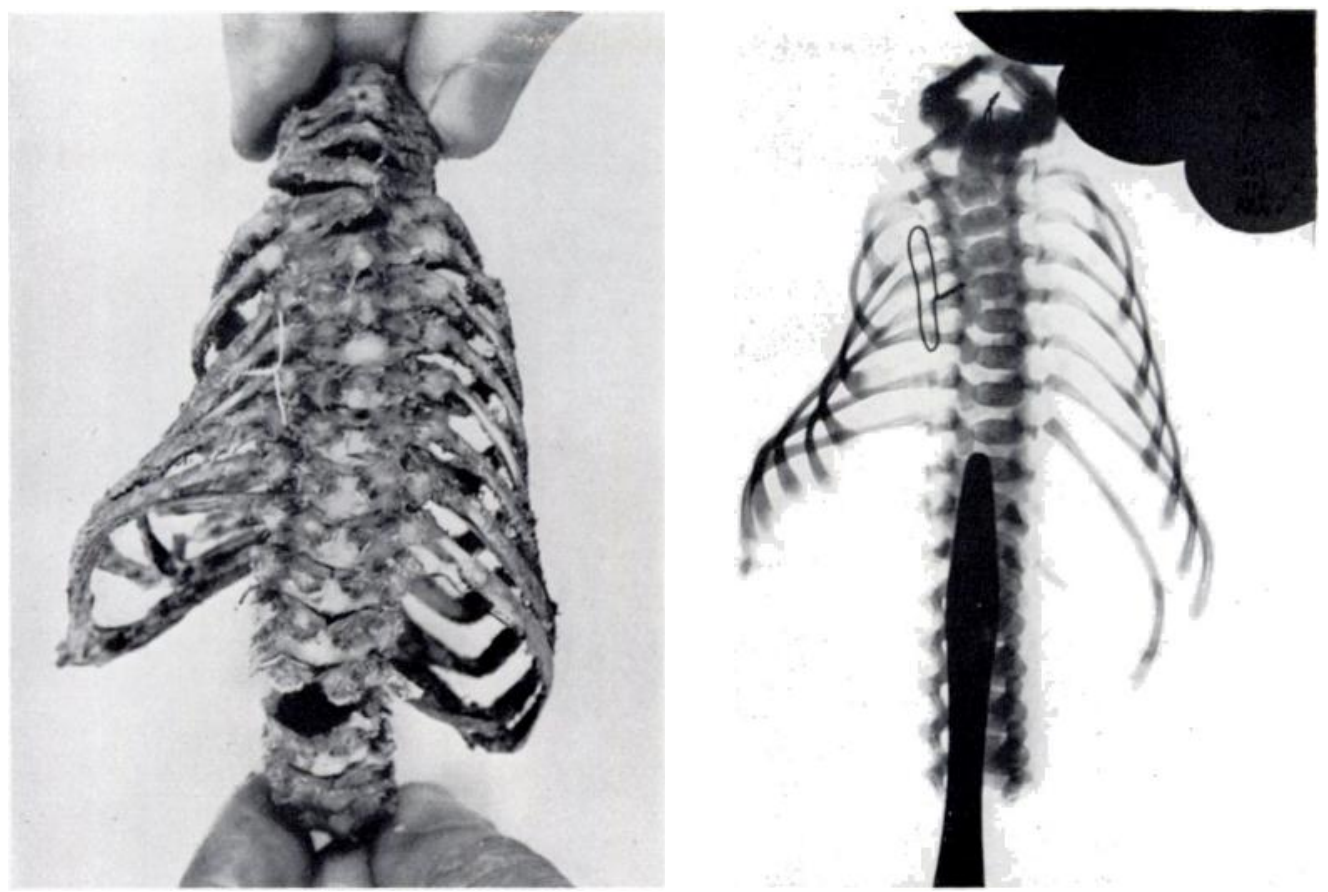

Fig. 15

Same spine as in Figures 13 and 14 specimen and radiograph with the spine flexed.

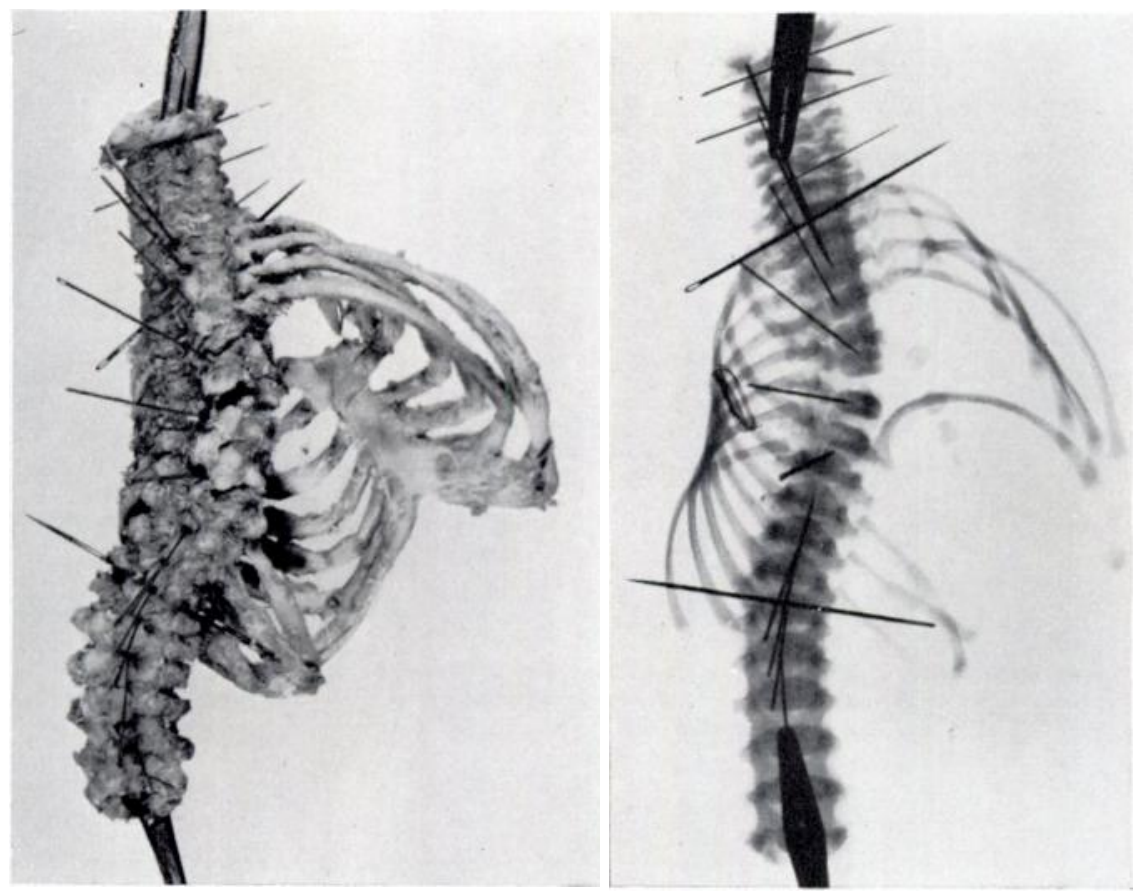

FIG. 16

In order to reproduce a deformity resembling scoliosis, even in a neonatal spine, many ligaments must be divided and a rotational subluxation produced. 


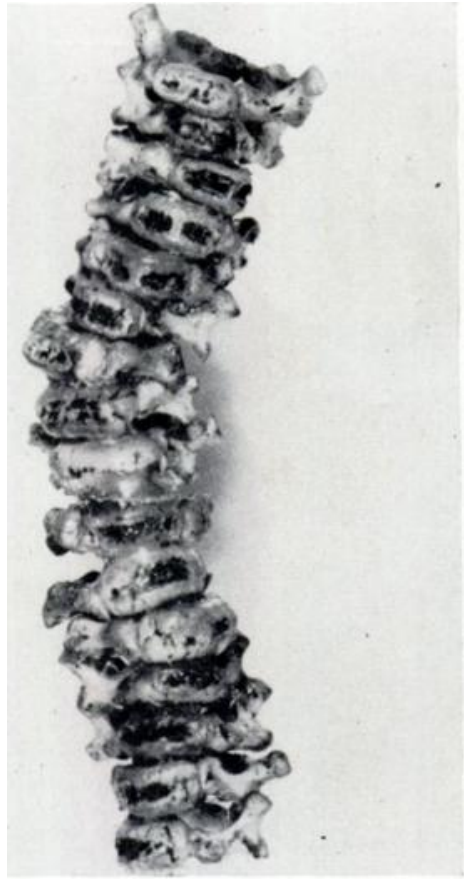

Fig. 17

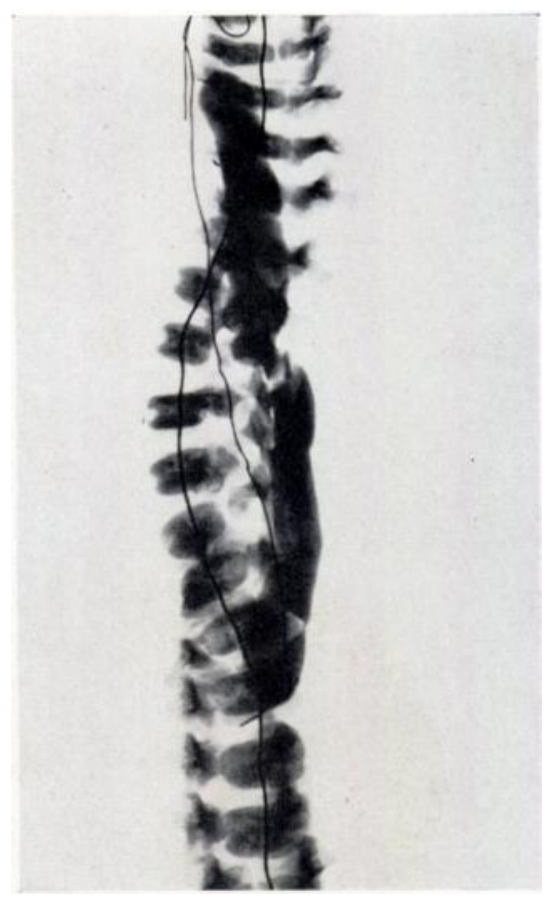

FIG. 18

Figure 17-Reconstruction of scoliotic spine by fastening vertebrae together in forced rotation but no lateral flexion. Figure 18-Radiograph of the artificial scoliosis. Shadows of plasticine mark areas where oblique fibres of erector spinae muscles have a mechanical advantage.

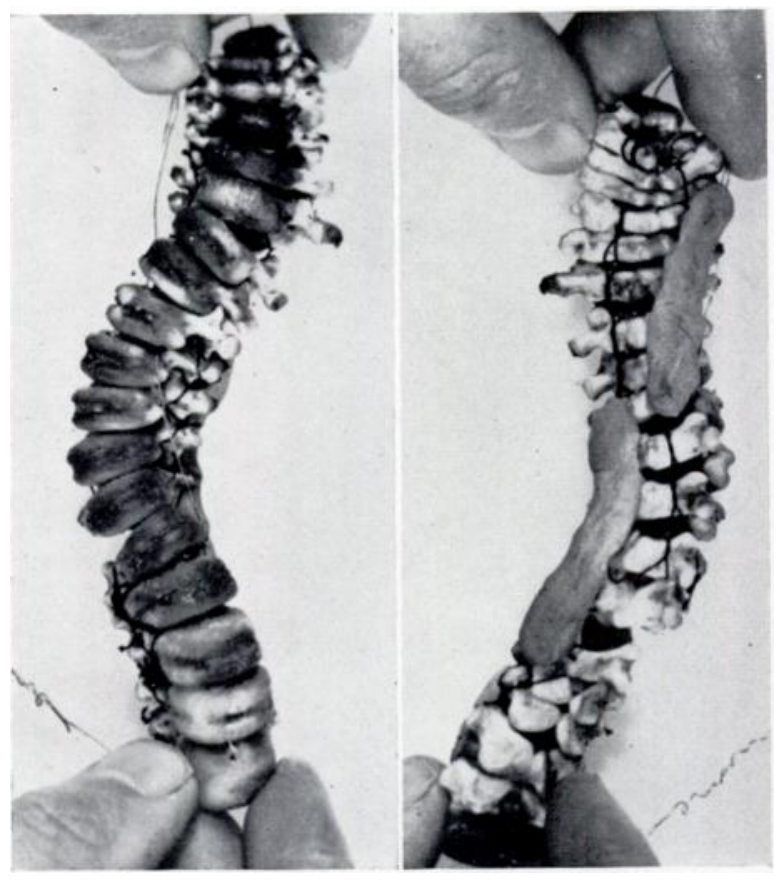

Fig. 19

Reconstruction of scoliotic spine by fastening vertebrae together in forced rotation but no lateral flexion. Plasticine marks areas where oblique fibres of erector spinae muscles have a mechanical advantage.

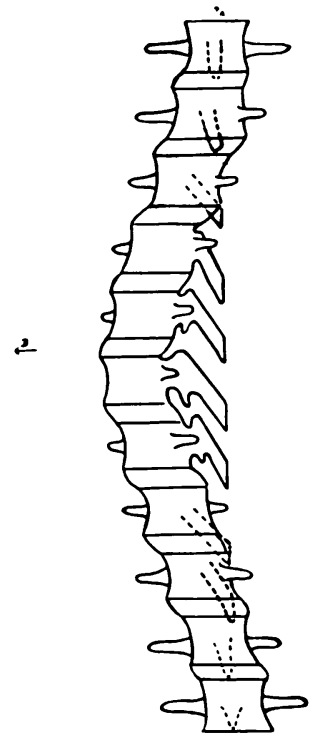

Fig. 20

Drawing to show that rotation in one direction in the upper part of the curve must bebalanced by an equal rotation in the opposite direction in the lower part of the curve. 


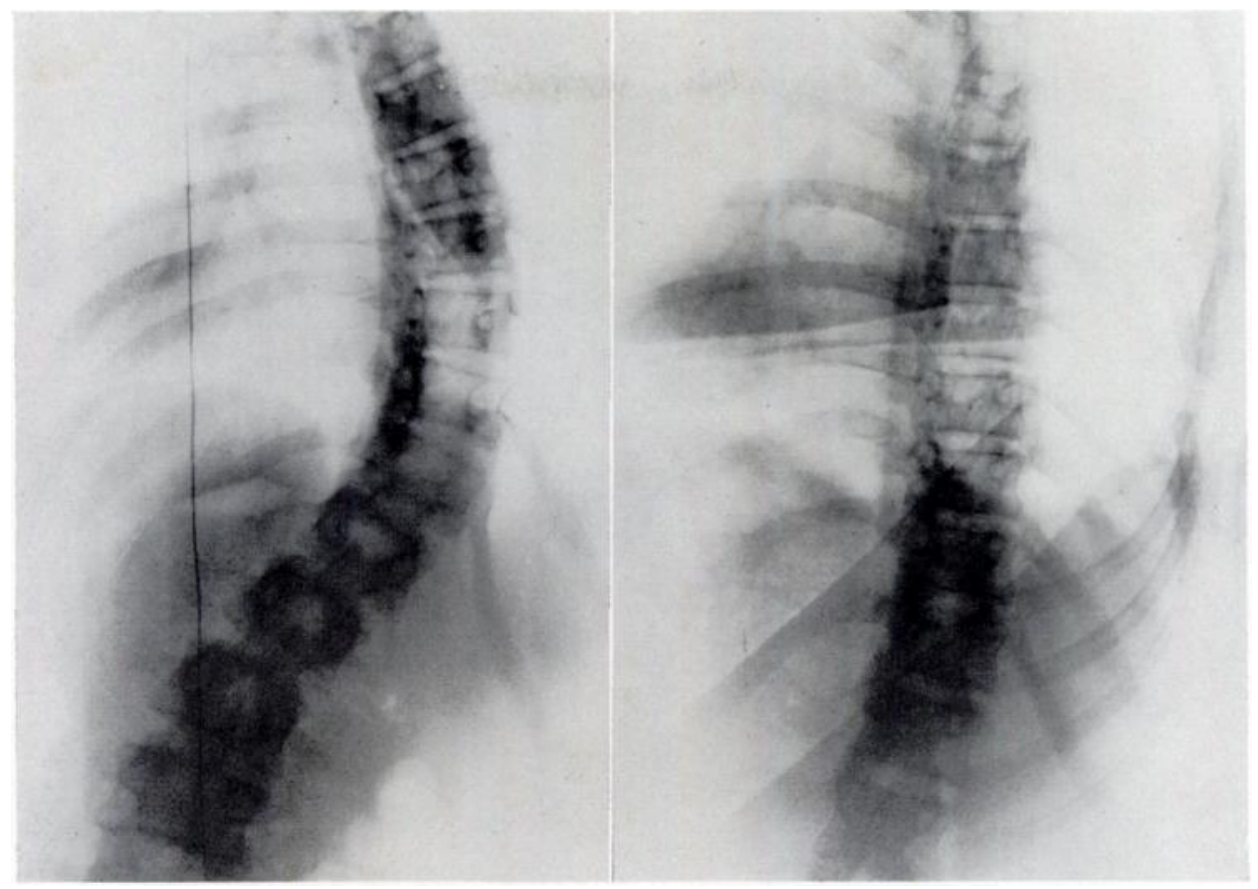

FIG 21

Lateral flexion type of scoliosis (with minimal rotation) before and after correction, which is easily obtained in this type.

is largely confined to the neural arch. At the centre of the curve the laminae and pedicles on the convex side are larger so that there is a bigger difference in both sagittal and longitudinal planes between the superior and inferior articular facets than on the concave side. At the ends of the curve the asymmetry is reversed (Figs. 22 to 28). Secondly, in consequence of the rotation, six secondary deforming factors come into action which inevitably tend to increase the deformity. (The deformity, incidentally, is often wrongly interpreted as a lateral flexion when it is really a lordosis (Figs. 29 and 30); in fact, but for the lordosis, the spine could never return to the mid-line and would be permanently out of balance.) Firstly, the normal action of the longitudinal fibres of the erector spinae muscle is to advance the vertebrae at the centre of their span. This forward movement is normally opposed by gravity. If the vertebrae are rotated their movement is unopposed, so that every muscular contraction pushes them farther from the mid-line and increases the lordosis (Fig. 31). Secondly, gravity acts asymmetrically, causes a secondary lateral flexion and also possibly checks growth on the concave side (Figs. 32 and 33). Thirdly, the deep transverse fibres of the erector spinae muscles in the upper part of the convexity and lower part of the concavity act more directly than their obliquely placed opponents and therefore have a mechanical advantage (Fig. 34). Fourthly, the distorted rib cage is both an obstacle to correction and itself creates a couple of forces which tends to increase rotation (Fig. 35). Fifthly, since the upper and lower surfaces of the vertebral body are not usually pa rallel, the effect of rotation is to direct the lower vertebral surface sideways (Figs. 36 and 37). Lastly, if fusion is performed before growth is complete the graft may act as a tether at the back. In this case continued growth of the vertebral bodies causes increased lordo sis and, in the presence of rotation, increased deviation from the mid-line (Figs. 38 to 41 ). O ccasionally one meets patients with scoliosis in whom " reverse rotation" occurs-that is, the rotation is increased on straightening the curve and decreased on increasing the curve (Figs. 42 and 43). Such patients are another illustration that there is no inevitable link bet ween rotation and lateral flexion. 


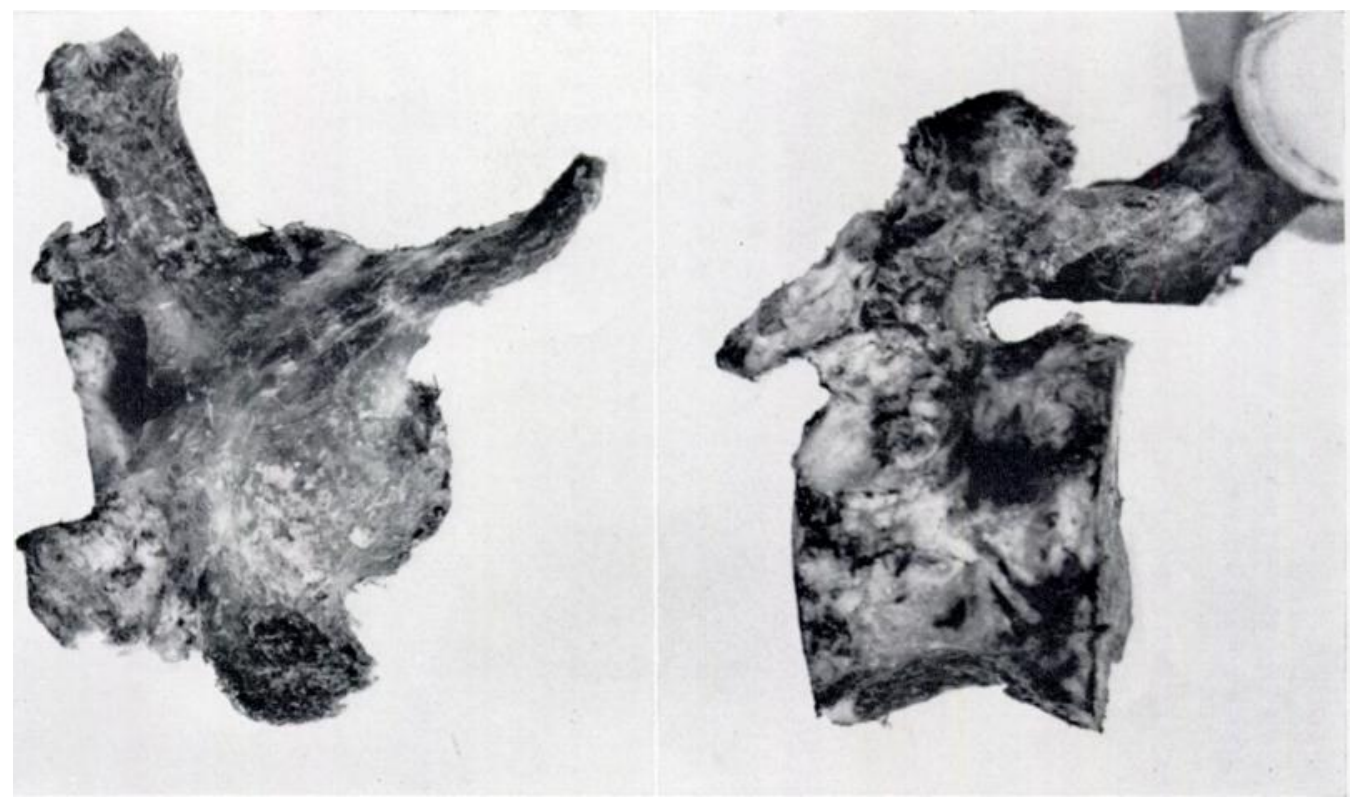

FIG. 22

Fig. 23

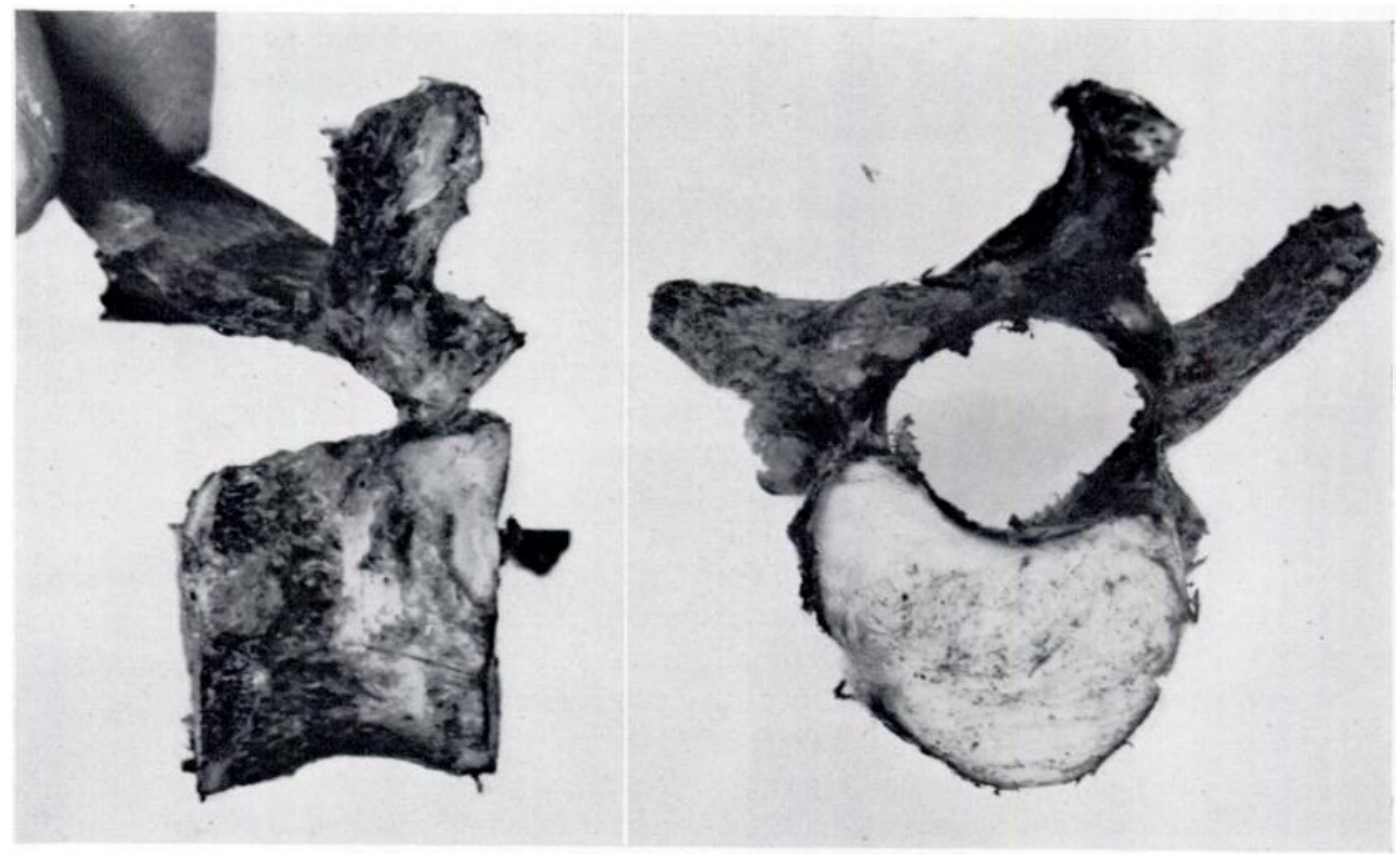

FIG. 24

FIG. 25

Views of scoliotic vertebra. Figure 22-Posterior view. Note hypertrophy of lamina on convex side. Figure 23Lateral view showing hypertrophy of pedicle on convex side. Figure 24-Lateral view of concave side. Figure 25-Axial view. Note hypertrophy of lamina and pedicle on convex side. Asymmetry of neural arch much more marked than of body. Bulk of erector spinae muscle is greater on convexity. 


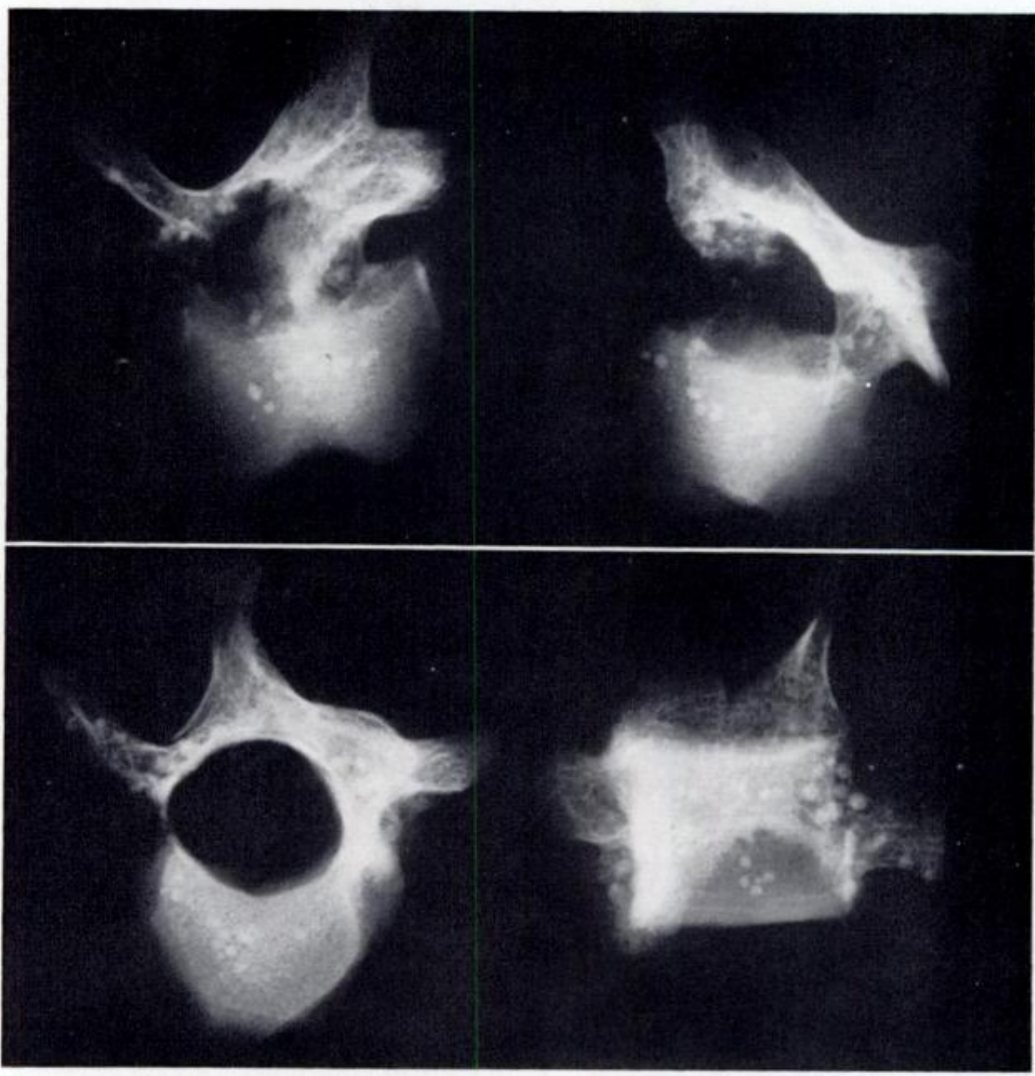

Fig. 26

Radiographs illustrating the features shown in Figures 21 to 24 .

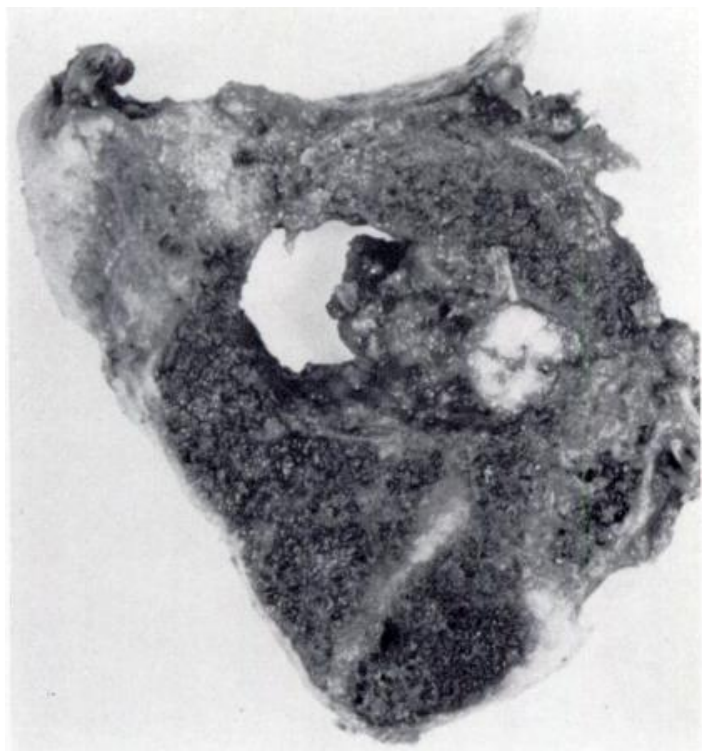

Fig. 27

Transverse section through spine at apex of scoliosis. Note lateral broadening of neural canal and spinal cord pressed against pedicles on concave side.

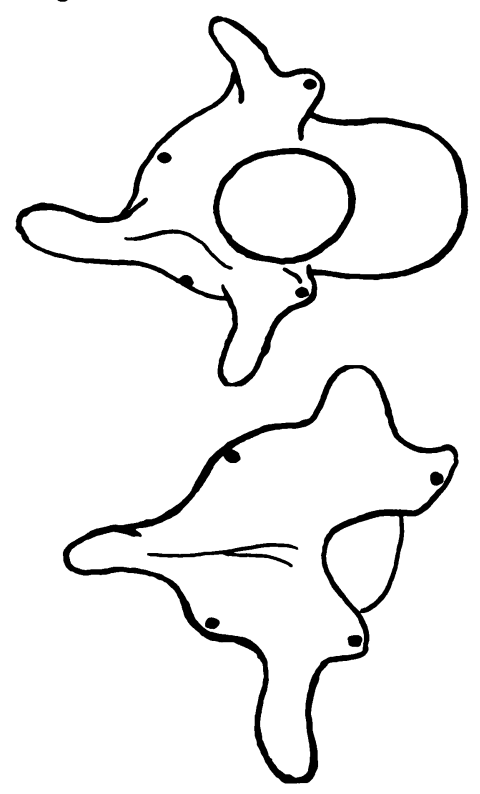

FIG. 28

Drawings of vertebral body. Dots mark articular facets. There is a greater distance in both longitudinal and sagittal planes between the facets on the convex side.

vOL. $40 \mathrm{~B}$, NO. 2, MAY 1958

L 


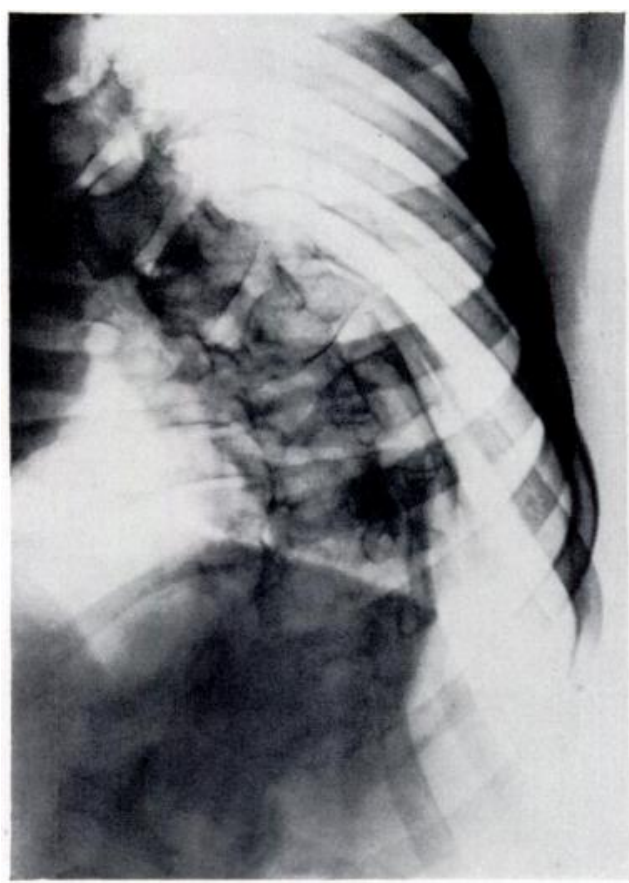

Fig. 29

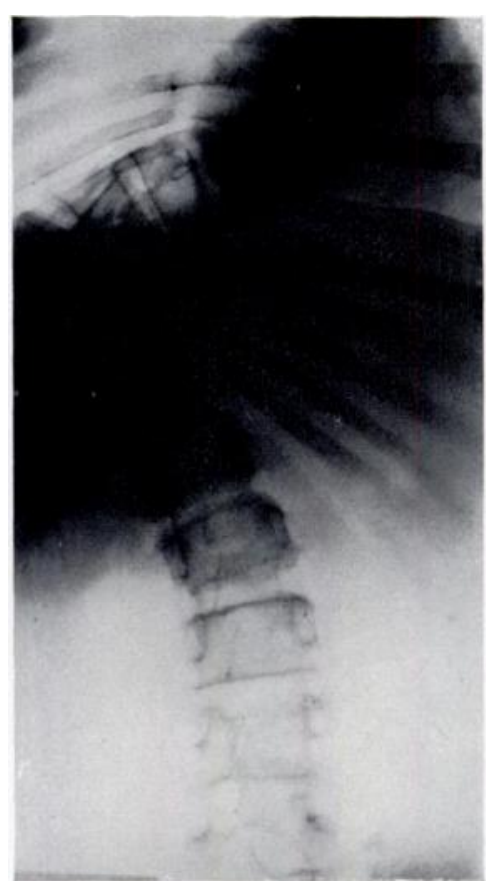

Fig. 30

Figure 29-Antero-posterior radiograph of 75 degrees of rotation of the vertebral bodies at the apex of the scoliosis. The vertebrae are seen in profile and apparent lateral flexion is really a lordosis. Figure $30-\mathrm{A}$ similar example.

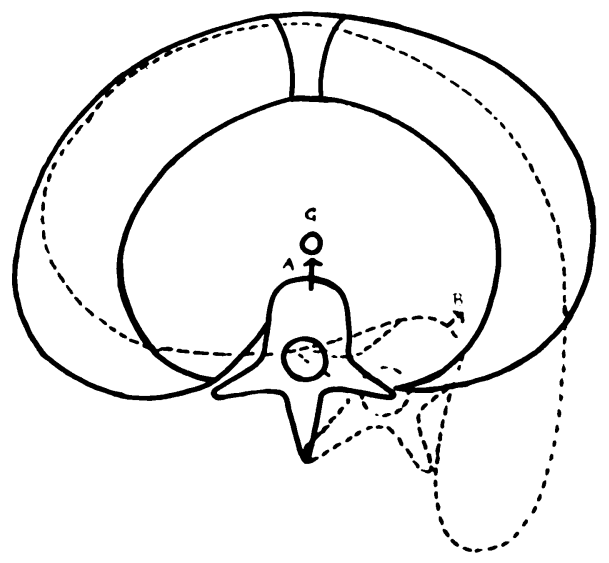

EFFECTS OF ROTATION (I)

\begin{abstract}
SHEWS : On extension rotated vertebra moves sideways when the spine is extended.

This movement is unopposed by gravity and tends to progress till the vertebra approaches the tib cage.
\end{abstract}

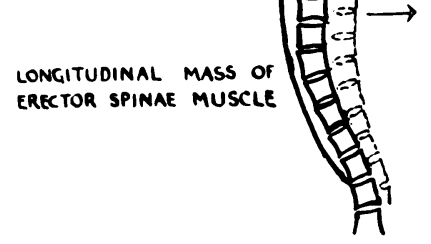

On extending spine, vertebrae at the centre of the extending section move forwards relative to those at the ends.

Fig. 31

Indicates that contraction of the longitudinal fibres of the erector spinae tend to make scoliotic vertebrae, which are already pointing laterally, move farther laterally unopposed by gravity. This forward movement of a normal vertebra is opposed by gravity. 


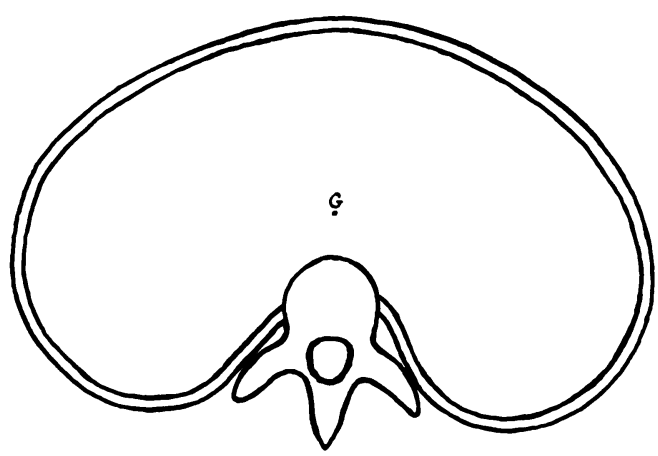

FiG. 32

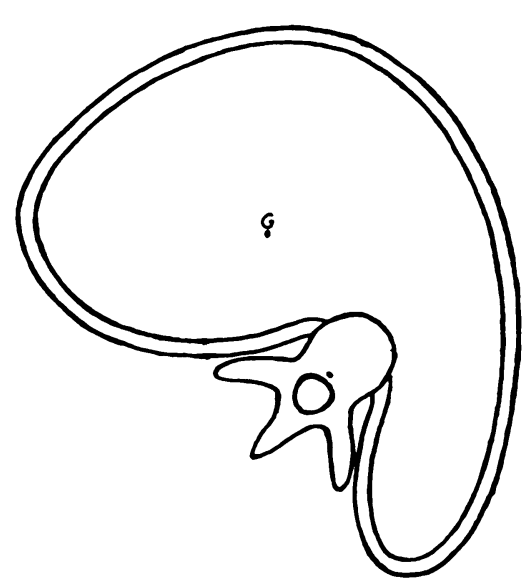

Fig. 33

Figure 32-Transverse section of normal thorax. Figure 33-Transverse section of scoliotic thorax. Note: 1) line of centre of gravity $(G)$ falls to one side of vertebral column causing secondary lateral flexion and unequal pressure on growing epiphyses; 2) vertebral body points sideways.

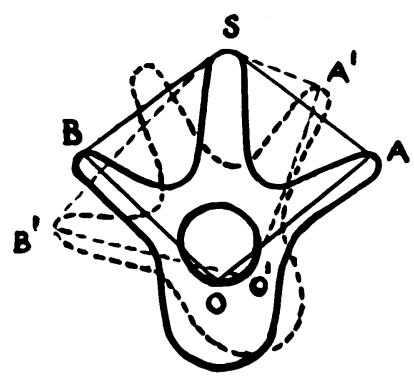

\section{EFFECTS OF ROTATION (II) \\ In neutral position $A B$ the rotary action of the deep oblique fibres of the erector spinae $a$ balanced $\angle S A O=\angle S B O$}

In the rotated position $A^{\prime} B^{\prime}$ $\angle S A^{\prime} O=\angle S B^{\circ} O^{\circ}$, therefore, other things being equal, the muscles on the convex side act at an

\section{advantage}

Fig. 34

Indicates that the oblique fibres of the erector spinae, which run from a spinous process to a transverse process of a lower vertebra, have a mechanical advantage on the convex side in the upper part of the curve and on the concave side in the lower part of the curve. These areas are indicated by plasticine shadows in Figures 18 and 19. 

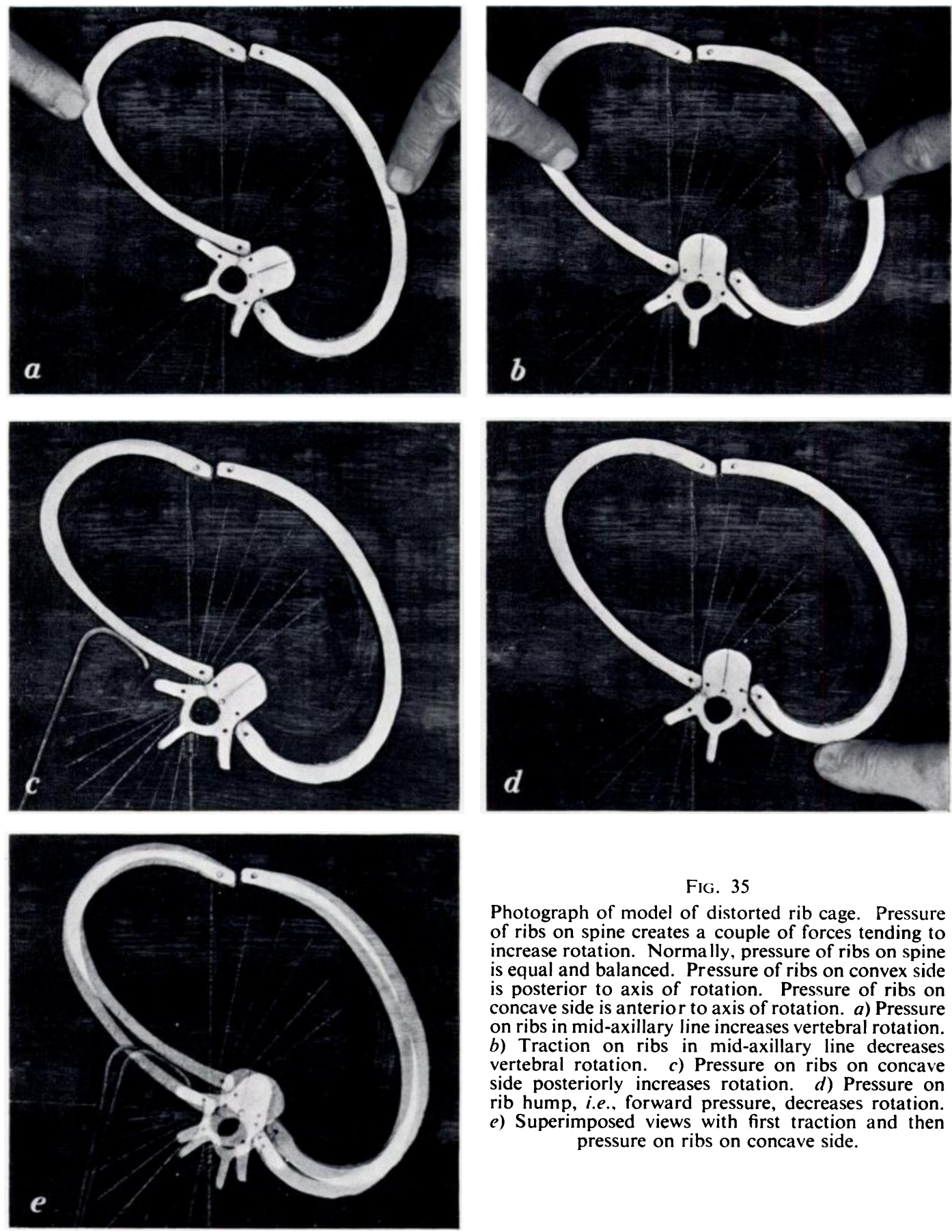

FIG. 35

Photograph of model of distorted rib cage. Pressure of ribs on spine creates a couple of forces tending to increase rotation. Normally, pressure of ribs on spine is equal and balanced. Pressure of ribs on convex side is posterior to axis of rotation. Pressure of ribs on concave side is anterior to axis of rotation. a) Pressure on ribs in mid-axillary line increases vertebral rotation. b) Traction on ribs in mid-axillary line decreases vertebral rotation. c) Pressure on ribs on concave side posteriorly increases rotation. d) Pressure on rib hump, i.e., forward pressure, decreases rotation. e) Superimposed views with first traction and then pressure on ribs on concave side. 


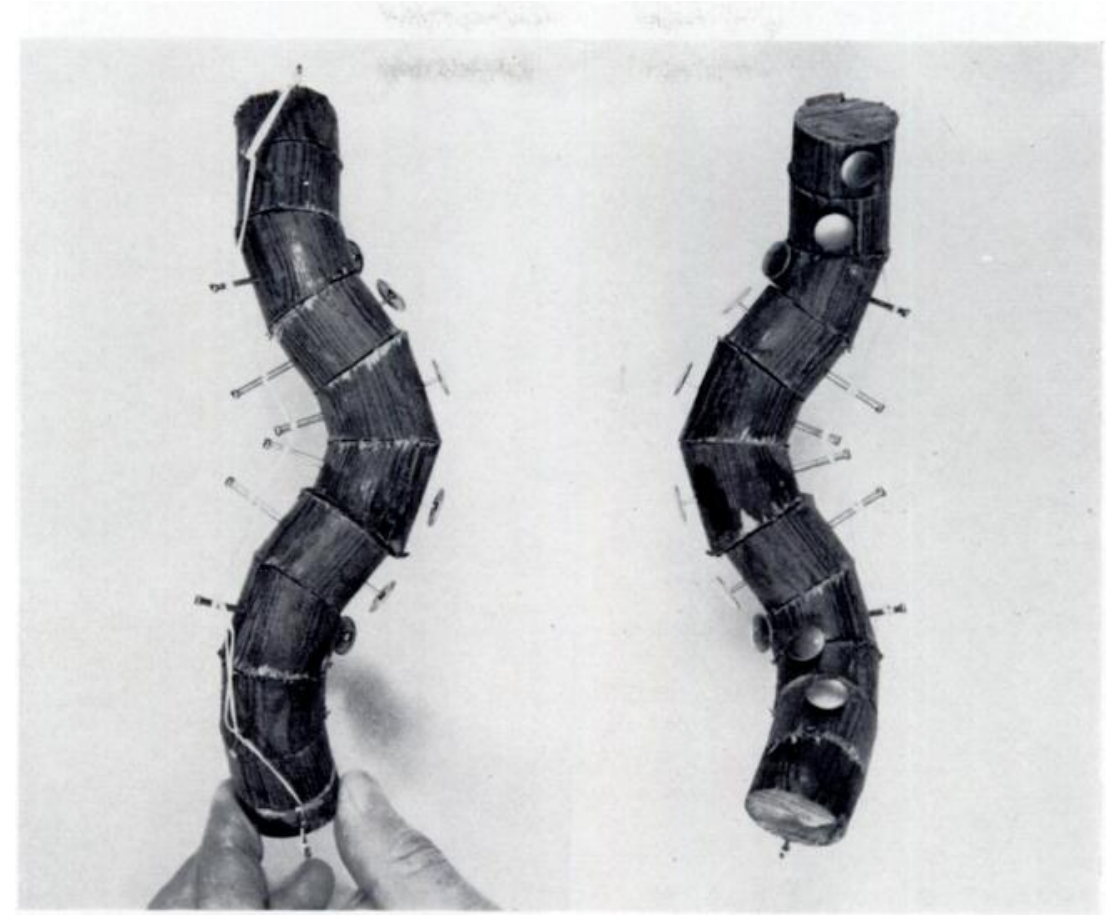

Fig. 36

Anterior and posterior aspects of a model of a scoliotic spine. Upper and lower vertebral surfaces are not parallel; therefore rotation alone will produce lateral deviation without any element of lateral flexion. Note in model lordosis at apex of curve (but for this, spine would not come back to the mid-line). Series of nails and string represents spinous processes. Line of drawing pins represents anterior longitudinal ligament.

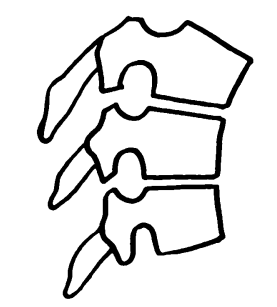

\section{LATERAL VIEW}

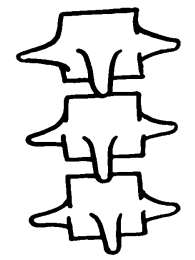

A-P VIEW

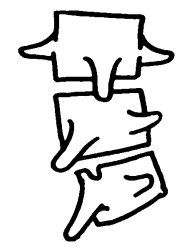

A-P VIEW OF ROTATED

Fig. 37

SPINE

Illustrates how rotation produces lateral inclination and lateral deviation without any lateral flexion in the presence of slight vertebral wedging. 


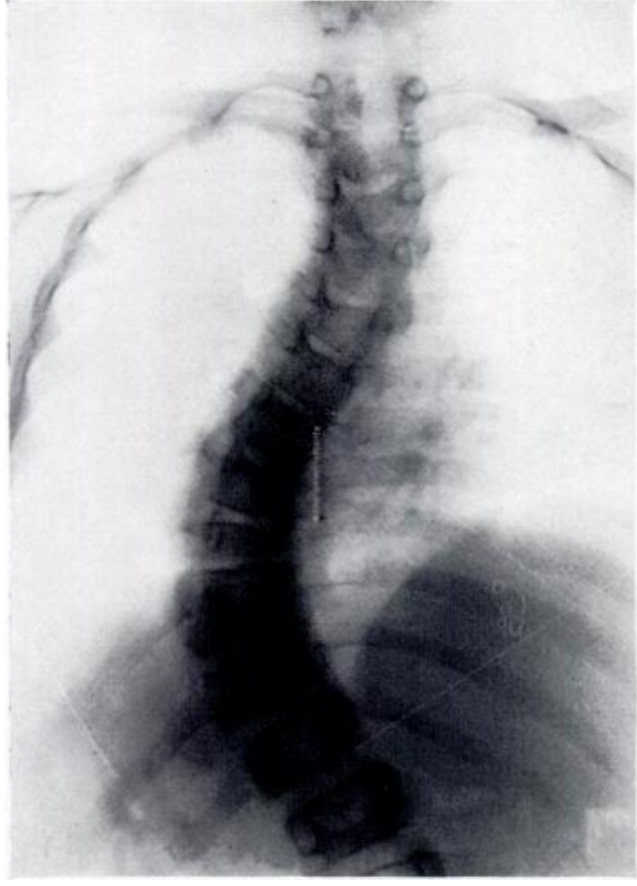

Fig. 38

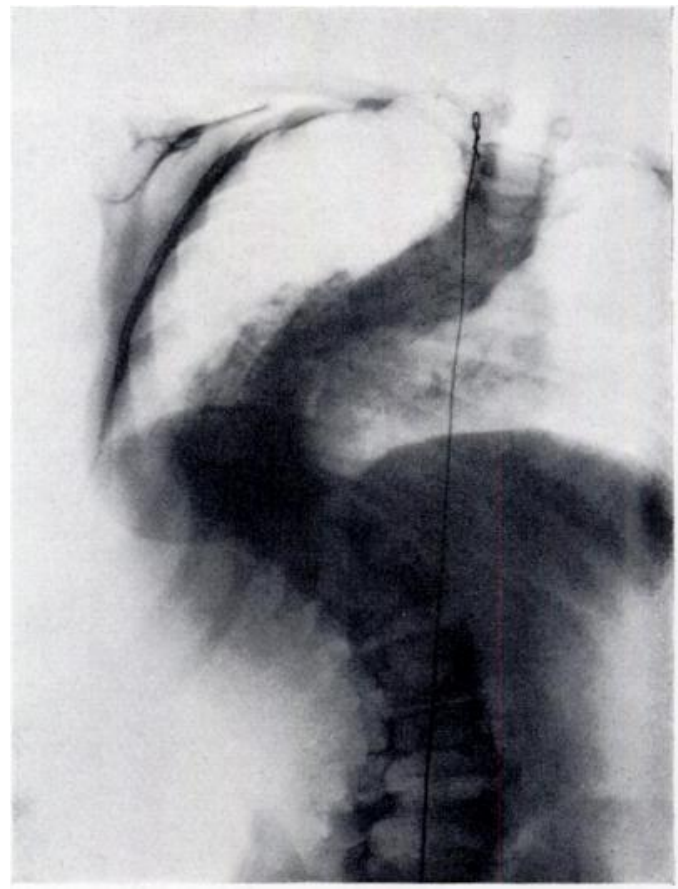

FIG. 39

Figure 38-Antero-posterior radiograph of spine before laminal fusion. Note rotation of vertebral bodies Figure 39-Four years later. Continued growth of the vertebral bodies has caused increased lordosis due to the tethering action of the laminal fusion. This gives a false appearance of increased lateral flexion in the antero-posterior radiographs.

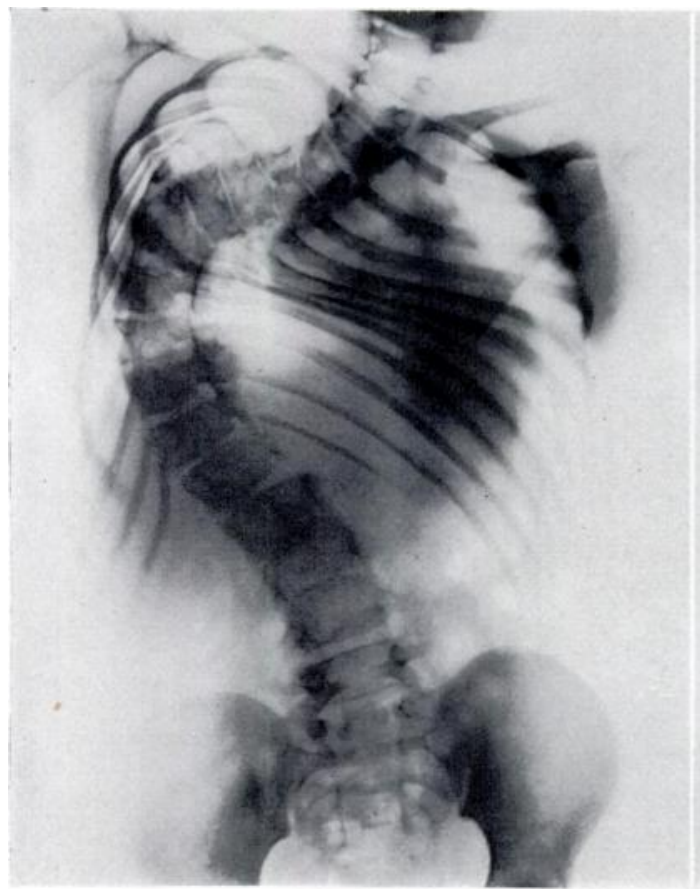

FIG. 40

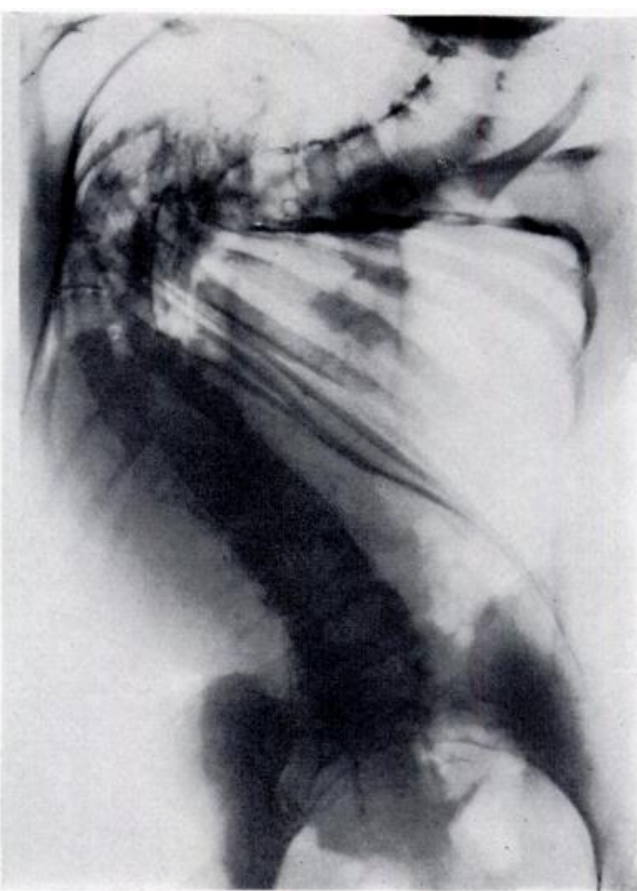

FIG. 41

Figure 40-Antero-posterior radiograph of spine before laminal fusion. Note rotation of vertebral bodies. Figure 41-Six years later. Continued growth of the vertebral bodies has caused increased lordosis due to the tethering action of the laminal fusion. This gives a false appearance of increased lateral flexion in the antero-posterior radiographs. (By courtesy of Mr E. N. Wardle.) 


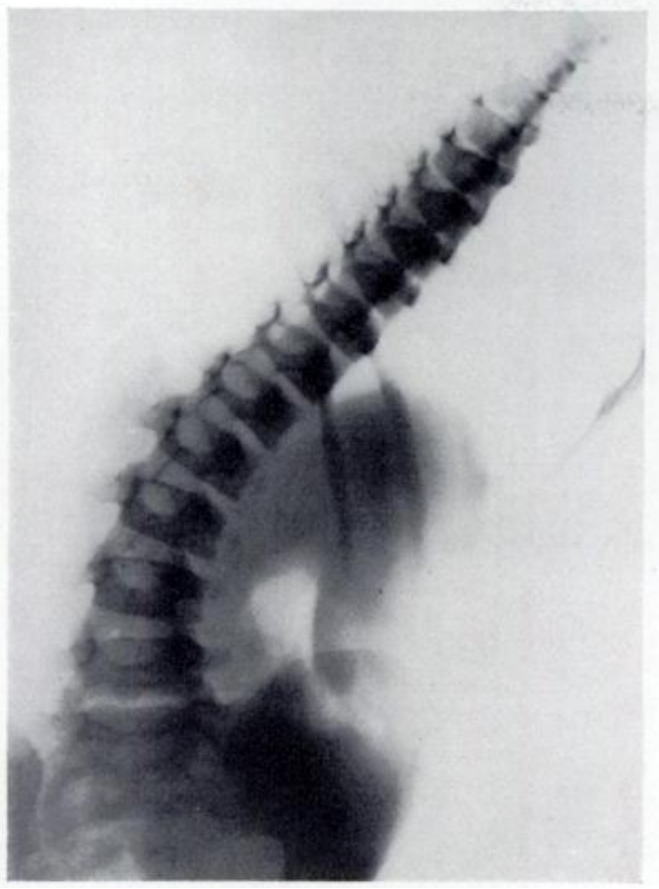

Fig. 42

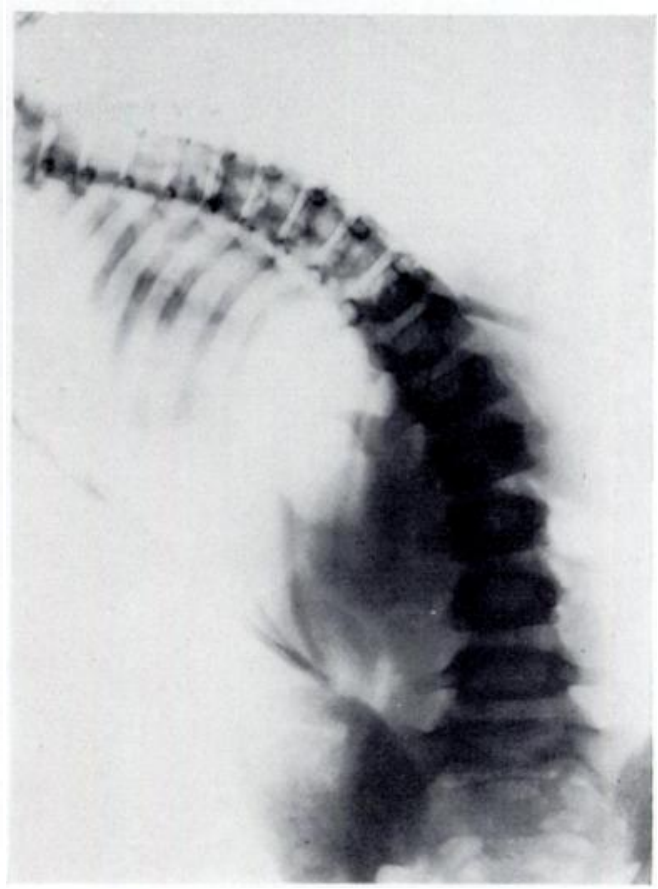

Fig. 43

Figure 42-In this patient's spine there was a slight lateral scoliosis to the left in the thoraco-lumbar region. When this was corrected by right lateral flexion there was rotation to the right. This is the opposite of the direction of rotation which would be expected if the classical theory were true. Figure 43-Lateral flexion in the opposite direction, which increases the deformity, makes the rotation disappear.

\section{SUMMARY}

The principle of Occam's razor proves nothing. Nevertheless, it is possible to explain all the phenomena of severe scoliosis on the basis of a primary rotation deformity alone. The typical rotation type of scoliotic deformity can be reproduced artificially by fitting vertebrae together in an abnormal rotatory relationship without any element of lateral flexion. From this, certain mechanical factors inevitably come into play which must tend to increase the deformity. Above all, the forces responsible for progressive scoliosis are dynamic and active, not just passive. The spine readily compensates for a passive, non-progressive deformity such as a simple wedge vertebra. It is my belief that rotation is usually the dominant factor and that correction and control of severe scoliosis can only be achieved by concentrating on the rotation deformity. I am well aware that this is an old idea but its essential truth has been insufficiently appreciated in recent years and we have not faced its full implications. Failure to correct rotation invites recurrence. Conversely, even a slight reduction in rotation usually produces a marked cosmetic improvement, often out of all proportion to the radiographic appearances.

\section{REFERENCES}

BAKKe, S. N. (1931): Röntgenologische Beobachtungen über die Bewegungen der Wirbelsäule. Acta Radiologica, Supplementum 13.

BegG, A. C., and FAlconer, M. A. (1949): Plain Radiography in Intraspinal Protrusion of Lumbar Intervertebral Disks. A Correlation with Operative Findings. British Journal of Surgery, 36, 225.

Brailsford, J. F. (1934): The Radiology of Bones and Joints. London: J. \&. A Churchill Ltd.

FICK, R. (1910): Handbuch der Anatomie und Mechanik der Gelenke unter Berücksichtigung der bewegenden Muskeln. Jena: G. Fischer.

Frazer, J. E. (1940): The Anatomy of the Human Skeleton. Fourth edition. London: J. \& A. Churchill Ltd.

VOL. 40 B, NO. 2, MAY 1958 
LockhaRT, R. D. (1934): The Action of Muscle, Vertebral Column, Hip and Shoulder Joint in Living Subjects. Kodak Medical Film Library, Anatomical Section, No. 238. Part 2, two reels. (In British Medical Association Film Library.)

LOVETT, R. W. (1905): Die Mechanik der normalen Wirbelsäule und ihr Verhältnis zur Skoliose. Zeitschrift für Orthopädische Chirurgie, 14, 399.

SCHULTHESS, W. (1899): Zur normalen und pathologischen Anatomie der jugendlichen Wirbelsäule. Zeitschrift für Orthopädische Chirurgie, 6, 399.

Somerville, E. W. (1952): Rotational Lordosis. The Development of the Single Curve. Journal of Bone and Joint Surgery, 34-B, 421.

Steindler, A. (1929): Diseases and Deformities of the Spine and Thorax. St Louis: The C. V. Mosby Company. Strasser, H. (1913): Lehrbuch der Muskel-und Gelenkmechanik, Band 2. Berlin: J. Springer.

TANZ, S. S. (1950): To-and-fro Motion Range at Fourth and Fifth Lumbar Interspaces. Journal of the Mount Sinai Hospital, 16, 303.

Virchow, H. (1907): Ueber die tiefen Rückenmuskeln des Menschen. Anatomischer Anzeiger, 30, Ergänzungsheft 91.

Weber, W., and Weber, E. (1836): Mechanik der menschlichen Gehwerkzeuge. Göttingen: in der Dieterichschen Buchhandlung.

WILES, P. (1935): Movements of the Lumbar Vertebrae during Flexion and Extension. Proceedings of the Royal Society of Medicine (Section of Orthopaedics), 28, 647. 